\title{
Auxiliary Proteins are the Predominant Determinants of Differential Efficacy of Clinical Candidates Acting as AMPA Receptor Positive Allosteric Modulators
}

\author{
Toshiyuki Ishii, Jacob R. Stolz, and Geoffrey T. Swanson
}

Department of Physiology, Nippon Medical School, Tokyo, Japan (T.I.); Department of Pharmacology, Feinberg School of Medicine, Northwestern University, Chicago, Illinois (T.I., J.R.S., G.T.S.); and Department of Neurobiology, Weinberg College of Arts and Sciences, Northwestern University, Evanston, Illinois (G.T.S.)

Received October 14, 2019; accepted February 7, 2020

\section{ABSTRACT}

Positive allosteric modulators (PAMs) of AMPA receptors boost cognitive performance in preclinical and clinical studies. Their therapeutic window is narrow, however, and clinical application will likely only occur if greater discrimination in activity is achieved. Toward that end, we compared the modulatory activity of two PAMs recently considered as clinical candidates, LY451395 (mibampator) and PF-04958242/BIIB104, on recombinant and native AMPA receptors (AMPARs). We found that the principle molecular determinant that shaped modulatory activity of both PAMs on deactivation (recombinant) and decay (synaptic) of AMPARs was the auxiliary protein incorporated into the receptor complexes. AMPARs containing the stargazin $/ \gamma 2$ transmembrane AMPAR regulatory protein (TARP) were slowed to a $>10$-fold degree by both PAMs as compared with those incorporating $\gamma 8$ TARP. Neither subunit composition nor flip/flop splice variation had substantive effect. Similarly, stargazin/ $\gamma 2$-containing mossy fiber EPSCs in cerebellar granule neurons were slowed to a $\sim 5$-fold greater degree than EPSCs in hippocampal CA1 pyramidal cell neurons, which express the $\gamma 8$ TARP. LY451395 exhibited greater efficacy than BIIB104 at both synapses. These studies provide insight into the receptor constituents that determine efficacy of sulfonamide PAMs. We conclude that compounds that discriminate between AMPARs complexed with distinct TARPs, and particularly those with lower stargazin/ $\gamma 2$ efficacy such as BIIB104, could act as viable procognitive therapeutics.

\section{SIGNIFICANCE STATEMENT}

Positive allosteric modulators (PAMs) of AMPA receptors enhance cognitive function in a variety of preclinical models. A clearer understanding of the critical determinants of PAM activity could yield critical insight into pathways to maximize their therapeutic index. Here we show that auxiliary proteins for AMPARs play a major, but thus far underappreciated, role in shaping recombinant and neuronal AMPAR modulation by two clinical candidate PAMs. These data will inform both clinical outcomes as well as future rational development of new modulators.

\section{Introduction}

Enhancement of cognitive function through pharmacological means has been a goal of decades of research. One strategy for achieving this objective has been potentiation of signaling by $\alpha$-amino-3-hydroxy-5-methyl-4-isoxazolepropionic acid receptors (AMPARs), the primary family of ionotropic glutamate receptors underlying excitatory synaptic transmission (Arai and Kessler, 2007; Partin, 2015). Neuronal membrane depolarization can be amplified or prolonged by AMPAR positive allosteric modulators (PAMs) (Ito et al., 1990; Arai and Kessler, 2007), which leads to diverse consequences that

This study was supported by the Pfizer Neuroscience Research Unit, Cambridge, MA (contract to G.T.S.), a grant from the Nippon Medical School Grant-in-Aid for Overseas Training (2017) funded by the Operating Costs Subsidies for Private Universities (to T.I.), and a Grant-in-Aid for Scientific Young Scientists (B) from JSPS [KAKENHI JP 17K16990] (to T.I.).

https://doi.org/10.1124/mol.119.118554. include altered synaptic plasticity, improved cognitive function, and amelioration of cognitive decline in preclinical models of neurologic dysfunction (Arai and Lynch, 1992; Granger et al., 1993; Johnson et al., 1999; reviewed in Partin, 2015). This therapeutic promise has been offset by a decades-long failure to translate animal and mechanistic studies into clinical success (Granger et al., 1993; Arai et al., 1996; Lynch et al., 2014). Despite improved cognitive task performance in small human studies (Ingvar et al., 1997; Goff et al., 2001), AMPAR PAMs have shown an overt lack of efficacy or dose-capping toxicity in larger patient populations (Black, 2005; Goff et al., 2008; Partin, 2015). Nonetheless, they continue to be attractive prospects as lead compounds for a range of disorders, including cognitive deficits (Chappell et al., 2007) and agitation and aggression in Alzheimer disease (Trzepacz et al., 2013) as well as cognitive deficits in schizophrenia (Millan et al., 2012; Shaffer et al., 2015; Ranganathan

ABBREVIATIONS: AMPA, $\alpha$-amino-3-hydroxy-5-methyl-4-isoxazolepropionic acid; AMPAR, AMPA receptor; BI, BIIB104; CGC, cerebellar granule cell; HEK293T/17, human embryonic kidney expressing T-antigen clone 17; i, flip; LBD, ligand-binding domain; LY, LY451395; o, flop; PAM, positive allosteric modulator; Stg, stargazin; sucrose-aCFS, sucrose-rich artificial cerebral spinal fluid; TARP, transmembrane AMPAR regulatory protein. 
et al., 2017; Shaffer, 2018). AMPAR PAMs built on an elongated arylpropylsulfonamide template have proved to be promising clinical candidates, partly because of their high AMPAR affinity (Jhee et al., 2006; Shaffer et al., 2015). Exemplars are the biarylpropylsulfonamide LY451395 (mibampator) (Shepherd et al., 2002; Jhee et al., 2006; Chappell et al., 2007; Trzepacz et al., 2013) and the tetrahydrofuranether PF-04958242 (Shaffer et al., 2015), which is now named BIIB104 following its purchase by Biogen from Pfizer (Groton, CT).

Both the procognitive and unfavorable side effects of AMPAR PAMs arise at least in part from their modulation of AMPAR gating (Shaffer et al., 2013). Alternative splicing of AMPAR subunit mRNAs produces two variants, flip (i) and flop (o), which act as a determinant of PAM efficacy on desensitization kinetics (Partin et al., 1994; Johansen et al., 1995; Jin et al., 2005; Partin, 2015). Less clear is the extent to which auxiliary proteins for AMPARs, such as the transmembrane AMPAR regulatory proteins (TARPs) (Greger et al., 2017), shape PAM activity on recombinant and neuronal AMPARs.

We compared the clinical candidates LY451395 and BIIB104 with respect to their activity on distinct receptor splice variants or on AMPARs containing two common auxiliary proteins, the TARPs stargazin (Stg, $\gamma 2$ ) and $\gamma 8$. Stargazin is an obligate component of synaptic AMPARs in cerebellar granule cells (CGCs) (Hashimoto et al., 1999; Chen et al., 2000), whereas $\gamma 8$ combines with AMPARs at Schaffer collateral synapses in hippocampal CA1 pyramidal neurons (Rouach et al., 2005). These two synapses were chosen because enhanced signaling at cerebellar synapses likely underlies deterioration of motor function (Zasadny et al., 2009; Shaffer et al., 2013, 2015) and Purkinje cell toxicity (Garthwaite and Garthwaite, 1991; Brorson et al., 1995) reported as prominent side effects of some PAMs, whereas modulation of hippocampal and cortical synapses potentially underlies their procognitive actions (Roberts et al., 2010; Kiss et al., 2011; Shaffer et al., 2015). Our principle discovery was that auxiliary protein incorporation in AMPARs far outweighs subunit composition or flip/flop splice variation as a determinant of PAM activity on biophysical parameters relevant to synaptic function. Furthermore, LY451395 prolonged deactivation of glutamate-evoked currents and decay of synaptic currents to a greater degree than BIIB104 in all comparisons except those from recombinant AMPARs containing Stg. These studies provide insight into the receptor constituents that determine efficacy of sulfonamide PAMs and suggest that improved selectivity for procognitive activity will require development of compounds with reduced sensitivity to the presence of the Stg auxiliary protein.

\section{Methods}

Animals. We used male (26) and female (18) C57Bl/6 mice (Charles River, Wilmington, MA) for these experiments. No sex dependency was noted in the hippocampal and cerebellar slice recordings. All animals included in this study were treated in accordance with the protocols approved by the Northwestern University's Institutional Animal Care and Use Committee. These protocols were consistent with the standards of care established by the Guide for the Care and Use of
Animals, edition 8, published by the US National Institutes of Health in 2011.

Materials. BIIB104 ( $N$-\{(3S,4S)-4-[4-(5-cyano-2-thienyl)phenoxy]tetrahydrofuran-3-yl\}) propane-2-sulfonamide) and LY451395 ( $N$-[(2R)-2-[4'-(2-methanesulfonamidoethyl)-[1,1'biphenyl]-4-yl]propyl]propane-2-sulfonamide) were synthesized and fully characterized by Neuroscience Chemistry at Pfizer Worldwide Research and Development to 99\% chemical purity and $100 \%$ enantiomeric excess. We used plasmid DNA expressing recombinant rat GluA1, GluA2, and GluA4 in this study. Stargazin and $\gamma 8$ plasmid DNAs were provided by Dr. Dane Chetkovich (Vanderbilt University Medical Center). Glutamate and all reagents were purchased from SigmaAldrich (St. Louis, MO).

Cell Culture and Transfection. Human embryonic kidney expressing T-antigen clone 17 (HEK293T/17) cells from American Type Culture Collections (Manassas, VA) were cultured in Dulbecco's modified essential medium (Corning Cellgro, Manassas, VA) supplemented with $10 \%$ heatinactivated fetal bovine serum (Gemini Bio-Products, West Sacramento, CA), $100 \mu \mathrm{g} / \mathrm{ml}$ penicillin, and $100 \mu \mathrm{g} / \mathrm{ml}$ streptomycin (Corning Cellgro) at $37^{\circ} \mathrm{C}$ with $5 \% \mathrm{CO}_{2}$. HEK293T/17 cells were not tested for mycoplasma before use. Transient transfections were performed according to the manufacturer's protocol using a ratio of $1 \mu \mathrm{g}$ cDNA to $3 \mu \mathrm{l}$ Mirius Bio Trans-IT reagent (Mirius Bio Corporation, Madison, WI). Enhanced green fluorescent protein was cotransfected $(50 \mathrm{ng})$ with receptor plasmid DNA to identify receptor-expressing cells in physiologic recordings. HEK293T/17 cells were transfected at ratios of 1:3 for AMPAR subunits and stargazin and 1:5 for AMPAR subunits and $\gamma 8$. Heteromeric receptor subunit cDNAs were transfected at a $1: 1$ ratio and $1: 1: 1$ for heteromeric subunits and stargazin or $\gamma 8$. After transfection of TARP-expressing plasmid DNA, the cell media was supplemented with $10 \mu \mathrm{M}$ 2,3-dihydroxy-6-nitro-7-sulfamoyl-benzo [f]quinoxaline-2,3-dione to prevent cell death by excitotoxicity.

Electrophysiological Recording from Recombinant Receptors. Whole-cell or outside-out patch recordings were made from transfected HEK293T/17 cells held in voltage clamp at hyperpolarized potentials. Currents were elicited by the rapid application of glutamate to receptor-expressing cells using a three-chambered flowpipe attached to a piezobimorph or a Siskiyou MXPZT-300 solution switcher (Siskiyou Corporation, Grants Pass, OR). Glutamate-evoked control currents were recorded before addition of the PAM to both external and glutamate solutions. For desensitization recordings, glutamate was applied for 1 second at $10 \mathrm{mM}$ in wholecell mode, and PAMs were applied at concentrations of 0.03-10 $\mu \mathrm{M}$. For deactivation recordings, glutamate was applied for 1 to 2 milliseconds to outside-out patches; the junction potential was recorded after each experiment to confirm the duration of the application. PAMs were used at $10 \mu \mathrm{M}$ in deactivation experiments. The external solution contained $150 \mathrm{mM} \mathrm{NaCl}, 2.8 \mathrm{mM} \mathrm{KCl}, 1.8 \mathrm{mM} \mathrm{CaCl}_{2}, 1.0 \mathrm{mM}$ $\mathrm{MgCl}_{2}, 10 \mathrm{mM}$ glucose, and $10 \mathrm{mM}$ Hepes, adjusted to $\mathrm{pH}$ 7.3. The internal solution contained $110 \mathrm{mM} \mathrm{CsF}, 30 \mathrm{mM} \mathrm{CsCl}$, $4 \mathrm{mM} \mathrm{NaCl}, 0.5 \mathrm{mM} \mathrm{CaCl}_{2}, 10 \mathrm{mM}$ Hepes, and $5 \mathrm{mM}$ EGTA, adjusted to $\mathrm{pH}$ 7.3.

Brain Slice Preparation and EPSC Recording. Acute hippocampal and cerebellar slices were prepared from juvenile $\mathrm{C} 57 \mathrm{Bl} / 6$ mice of either gender in accordance with the protocols approved by the Institutional Animal Care and Use 
Committee. Ages were P17-P28 for hippocampal slices and P19-P32 for cerebellar slices. Mice were anesthetized with intraperitoneal xylazine $(10 \mathrm{mg} / \mathrm{kg})$ and ketamine $(100 \mathrm{mg} / \mathrm{kg})$ before transcardial perfusion with ice-cold, sucrose-rich artificial cerebral spinal fluid (sucrose-aCSF) containing $85 \mathrm{mM}$ $\mathrm{NaCl}, 2.5 \mathrm{mM} \mathrm{KCl}, 1.25 \mathrm{mM} \mathrm{NaH} \mathrm{PO}_{4}, 25 \mathrm{mM} \mathrm{NaHCO}$, $75 \mathrm{mM}$ sucrose, $25 \mathrm{mM}$ glucose, $10 \mu \mathrm{M}$ DL-APV, $100 \mu \mathrm{M}$ kynurenate, $0.5 \mathrm{mM} \mathrm{Na}$ L-ascorbate, $0.5 \mathrm{mM} \mathrm{CaCl}_{2}$, and $4 \mathrm{mM}$ $\mathrm{MgCl}_{2}$ oxygenated with $95 \% \mathrm{O}_{2} / 5 \% \mathrm{CO}_{2}$. Following perfusion, the mice were rapidly decapitated, and horizontal hippocampal slices $(350 \mu \mathrm{m})$ or parasagittal cerebellar slices $(250 \mu \mathrm{m})$ were prepared in sucrose-aCSF using a Leica VT1200S vibratome (Leica Biosystems, Buffalo Grove, IL). The slices were initially warmed to $30^{\circ} \mathrm{C}$ in oxygenated sucrose-aCSF and then returned to room temperature. They were then transferred to oxygenated aCSF containing $125 \mathrm{mM} \mathrm{NaCl}$, $2.4 \mathrm{mM} \mathrm{KCl}, 1.2 \mathrm{mM} \mathrm{NaH} \mathrm{PO}_{4}, 25 \mathrm{mM} \mathrm{NaHCO}, 25 \mathrm{mM}$ glucose, $2 \mathrm{mM} \mathrm{CaCl}_{2}$, and $1 \mathrm{mM} \mathrm{MgCl}_{2}$ for at least 1 hour prior to recording. During recording, the slices were continuously perfused with oxygenated aCSF at room temperature $\left(25^{\circ} \mathrm{C}\right)$. PAMs were bath-applied at either 0.03 or $1 \mu \mathrm{M}$.

Hippocampal CA1 pyramidal neurons and cerebellar granule cells were visually identified using a BX51WI fixed-stage upright microscope (Olympus, Center Valley, PA) and subsequently used for whole-cell patch clamp recordings with a MultiClamp 700A amplifier (Molecular Devices, Sunnyvale, CA). Borosilicate glass recording electrodes had tip resistances of 4-7 M $\Omega$, were filled with an internal recording solution containing $95 \mathrm{mM} \mathrm{CsF}, 25 \mathrm{mM} \mathrm{CsCl}, 10 \mathrm{mM}$ HEPES, $10 \mathrm{mM}$ EGTA, $2 \mathrm{mM} \mathrm{NaCl}, 2 \mathrm{mM}$ Mg-ATP, $10 \mathrm{mM}$ QX-314, $5 \mathrm{mM}$ TEA-Cl, and $5 \mathrm{mM}$ 4-AP, and were adjusted to a $\mathrm{pH}$ of 7.3 to 7.4 with $\mathrm{CsOH}$. All cells were held at $-70 \mathrm{mV}$ for the duration of the voltage clamp experiments. Cells were maintained in aCSF containing the $\mathrm{GABA}_{\mathrm{A}}$ receptor antagonists $10 \mu \mathrm{M}$ bicuculline and $50 \mu \mathrm{M}$ picrotoxin and NMDA receptor antagonist $50 \mu \mathrm{M}$ D-APV. PAMs were bath-applied for at least 10 minutes before acquisition for analysis. Evoked EPSCs were elicited at $0.05 \mathrm{~Hz}$ using a glass monopolar electrode positioned in the stratum radiatum (for hippocampal CA1 EPSCs) or the granule cell layer (for CGCs). Pairing stimulations occurred with an interstimulus interval of 40 milliseconds.

Analysis of recordings was carried out with Clampfit10 (Molecular Devices). The degree of desensitization was calculated as the inverse of the ratio between the current amplitude at the end of the 1-second application and the peak amplitude. Desensitization-concentration response curves were fitted with logistic functions with variable Hill slopes. Some fits were constrained to a maximum value or in their slope as required. Weighted mean deactivation $\tau_{\text {deact }}$ values were calculated from bi-exponential fits to currents evoked by 1 to 2 millisecond glutamate applications in outside-out patch recordings. Total acquisition time for these recordings was 2 seconds, and fits were generated from records that captured at least 10-times the mean weighted time constant under each condition.

Statistics. A target sample size was specified before acquisition of each type of acquisition; the final numbers varied because of imposition of criteria such as maximal rise time of currents. In some cases, additional data were collected because variation in measured parameters was unexpectedly large or because imposition of criteria reduced the recordings in a group to an unacceptably low number. Summary data are presented as mean \pm S.D. PAM actions on current kinetics were tested for statistical significance using paired Student's $t$ tests. Fold change data were log-transformed before analysis using an unpaired Student's $t$ test with Welch's correction; the decision to log-transform this data was made prior to acquisition. This study was exploratory in nature; as such, the $P$ values given are descriptive and should not be interpreted as testing a specific hypothesis. All statistical tests were performed using Prism 7.0 (GraphPad Software, La Jolla, CA).

\section{Results}

The pharmacological activity of BIIB104 was characterized previously in calcium imaging and electrophysiological experiments (Shaffer et al., 2015), which revealed a higher potency on human recombinant GluA2(i) receptors than GluA2(o) receptors. These studies did not resolve if the PAM completely eliminated desensitization in AMPARs or to what extent deactivation was subject to modulation. To determine these and other aspects of their activity on AMPARs, we compared positive modulation of a variety of homomeric and heteromeric recombinant AMPARs by BIIB104 (BI) and LY451395 (LY) (Fig. 1A). The comparison between the compounds was performed because it seemed possible that salient differences in their actions could inform future clinical assessments of BI given that in two Phase 2 trials (Chappell et al., 2007; Trzepacz et al., 2013), LY was evaluated at 1/5 to $1 / 15$ of its maximum tolerated dose in patients with Alzheimer disease because of "toxicologic issues" (Chappell et al., 2007), which were likely caused by overactivation of AMPARs. PAM activity was tested in voltage-clamp recordings from HEK293 cells expressing the AMPARs GluA1, A2, and A4 receptors containing both flip and flop splice variants and in combination with either $\mathrm{Stg} / \gamma 2$ or $\gamma 8$ TARPs. Glutamate $(10 \mathrm{mM})$ was fast-applied for 1 second (desensitization) to whole cells or to outside-out patches for 1 to 2 milliseconds (deactivation) with a submillisecond solution exchange time to resolve rapid kinetics of desensitization and deactivation.

BIIB104 and LY451395 are Flip-Selective AMPAR PAMs that Completely Eliminate Desensitization. Our initial studies determined how BI and LY altered desensitization of homomeric AMPARs formed from flip and flop splice isoforms of two subunits, GluA1 and GluA4. These experiments were carried out to classify the PAMs into previously established groups of those compounds that predominantly slowed desensitization, deactivation, or both functional parameters (Arai and Kessler, 2007). Both BI and LY profoundly increased the peak amplitude of glutamate-evoked currents and eliminated desensitization of homomeric GluA1(i) AMPARs at an initial test concentration of $10 \mu \mathrm{M}$ (Fig. 1B). In the representative traces shown, the black traces are the glutamate-evoked control currents, and the colored traces are taken following wash-in of BI (red) or LY (blue). The PAMs were less efficacious on homomeric GluA1(o) receptors; currents were potentiated to a lesser degree, and desensitization was slowed but not wholly eliminated (Fig. 1B). The potency of the PAMs was compared by fitting concentrationresponse curves to data collected at modulator concentrations ranging from 0.03 to $10 \mu \mathrm{M}$. The graph in Fig. 1C shows the concentration-response relationships for the percent desensitization of glutamate-evoked currents from GluA1(i) and 
A

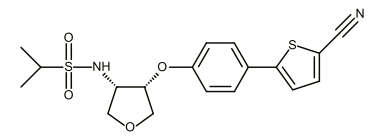

BIIB104

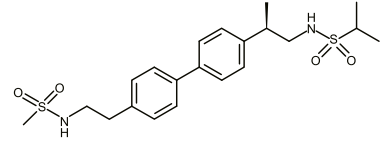

LY451395
B

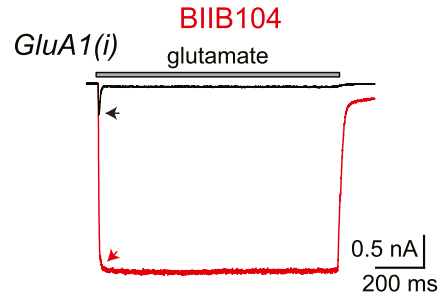

GluA1(o)

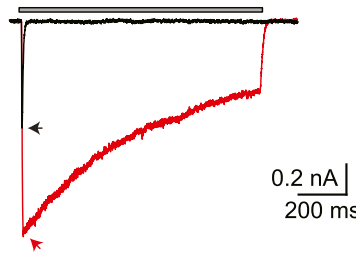

D

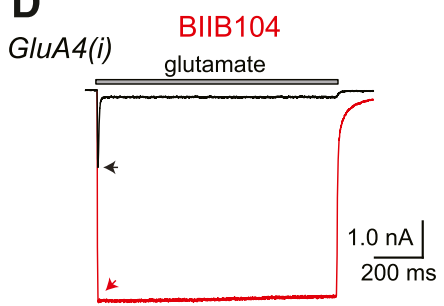

GluA4(o)

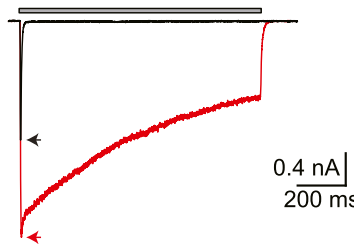

LY451395
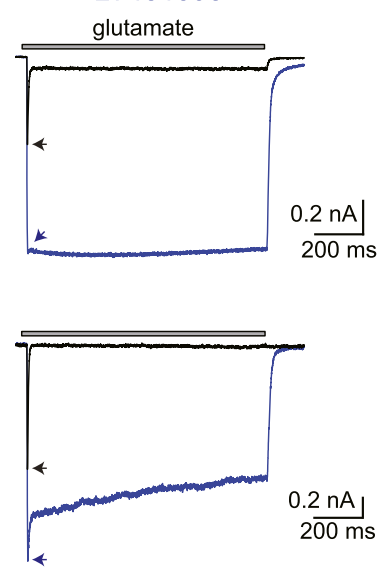

LY451395

glutamate
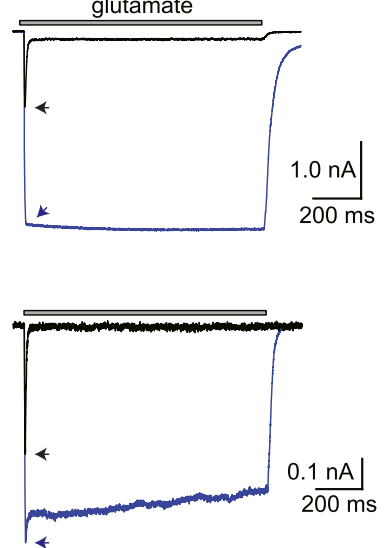

C

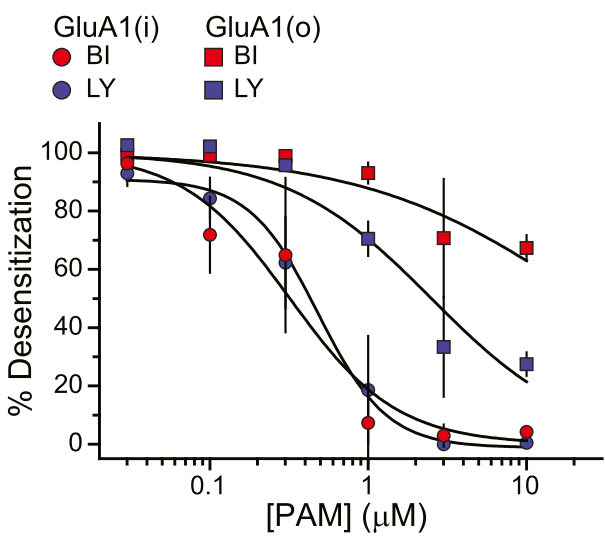

E

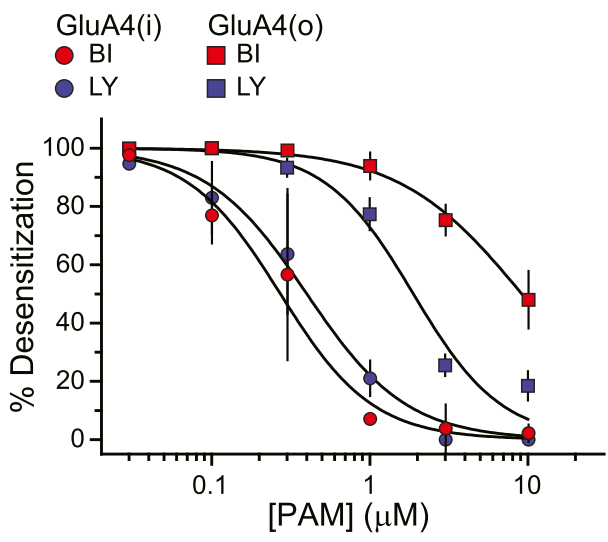

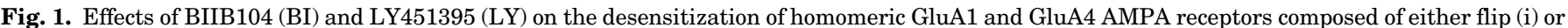

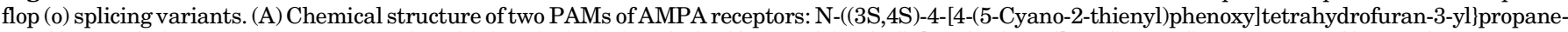

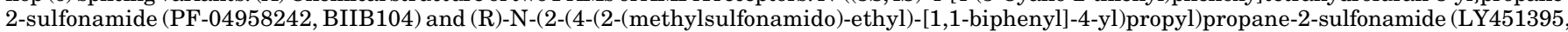

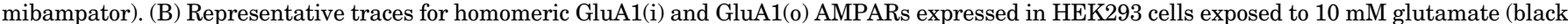

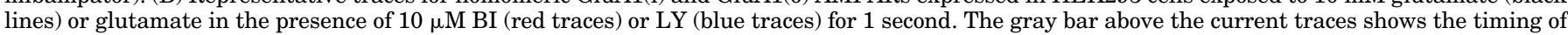

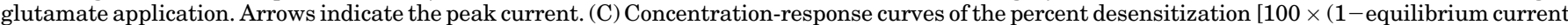

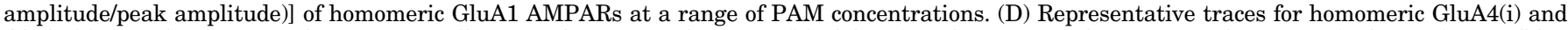

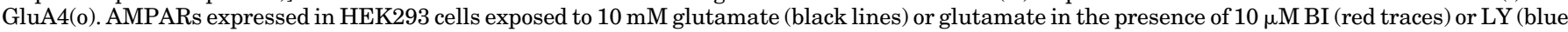

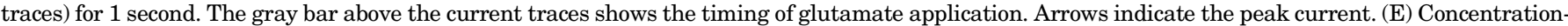

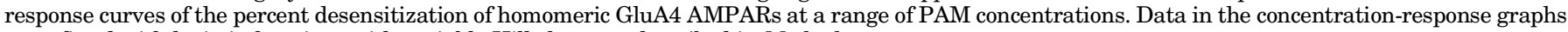
were fitted with logistic functions with variable Hill slopes as described in Methods.

GluA1(o) receptors, measured at the end of the 1-second agonist application (Fig. 1C). BI and LY were roughly equipotent on homomeric GluA1(i) receptors, with the following $\mathrm{EC}_{50}$ values: $\mathrm{BI} 0.3 \mu \mathrm{M}(95 \%$ confidence interval of $0.2-0.4$ $\mu \mathrm{M})$ and LY $0.5 \mu \mathrm{M}(0.3-0.7 \mu \mathrm{M})$ for GluA1(i) and BI $\sim 22 \mu \mathrm{M}$ and LY $2.2 \mu \mathrm{M}(1.7-2.9 \mu \mathrm{M})$ for GluA1(o).

The flip splice isoform selectivity was recapitulated and nearly indistinguishable for a second type of homomeric AMPARs, those formed from GluA4 subunits (Fig. 1, D and E). Both PAMs were more potent on GluA4(i) and at saturating concentrations that completely eliminated desensitization (Fig. 1D). BI partially occluded desensitization on GluA4(o) receptors at the highest concentration of $10 \mu \mathrm{M}$, whereas LY prevented all but a small desensitizing component. Concentration-response curves for the percent desensitization yielded $\mathrm{EC}_{50}$ values that were very close to those observed previously with GluA1. Those fitted $\mathrm{EC}_{50}$ values were BI $0.30 \mu \mathrm{M}(95 \%$ confidence interval of $0.2-0.4 \mu \mathrm{M})$ and LY $0.40 \mu \mathrm{M}(0.3-0.5 \mu \mathrm{M})$ for GluA4(i) and BI $\sim 9 \mu \mathrm{M}$ and LY $1.9 \mu \mathrm{M}(1.6-2.2 \mu \mathrm{M})$ for GluA4(o). Clearly, the fits to GluA1(o) 
A

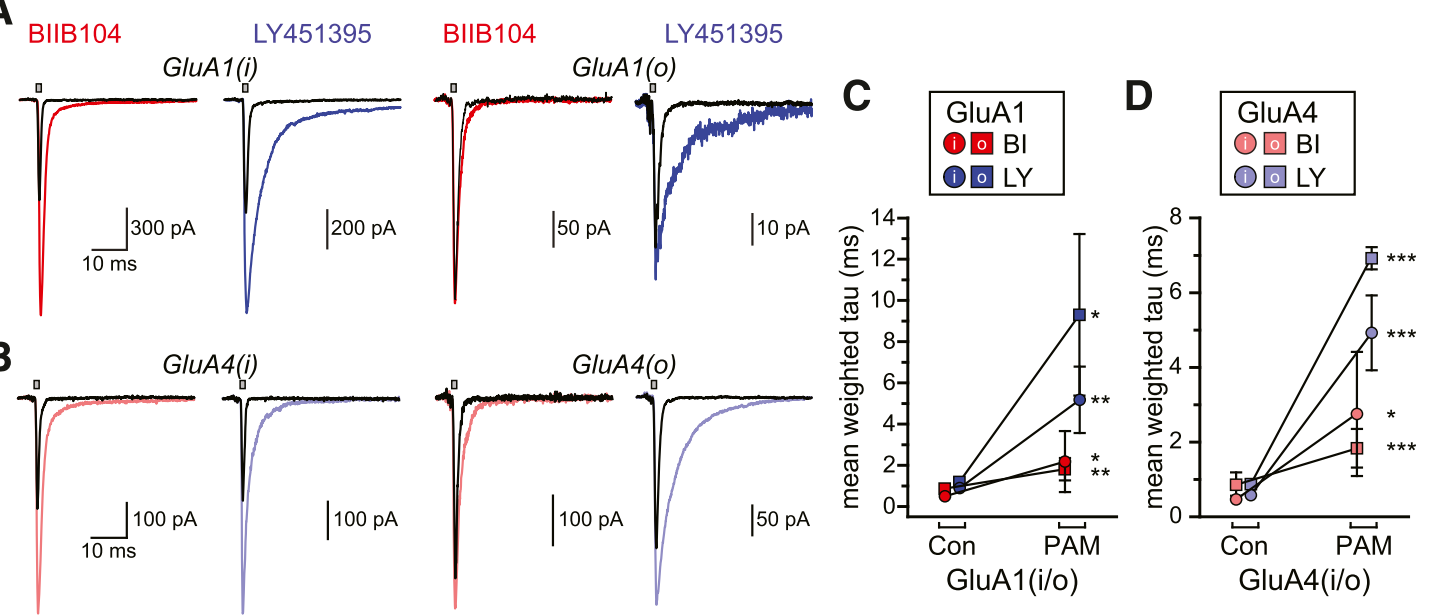

E

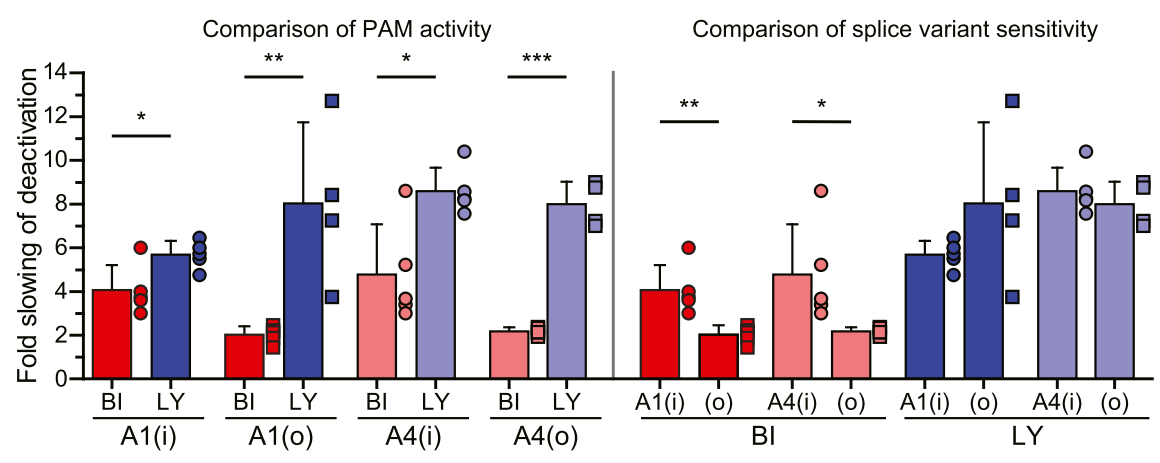

F

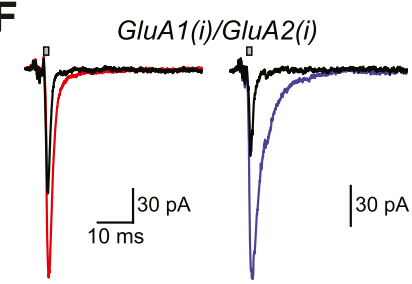

G

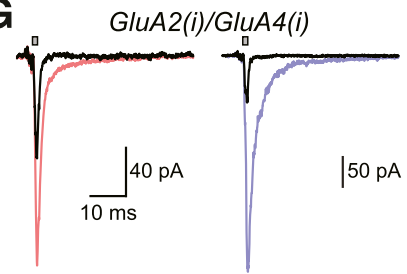

GluA1(o)/GluA2(i)

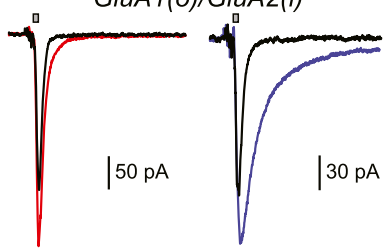

GluA2(i)/GluA4(o)

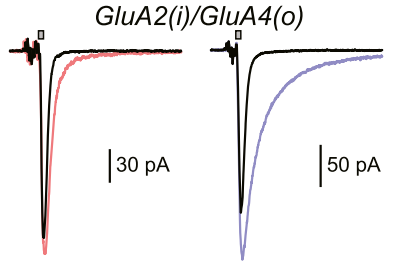

H
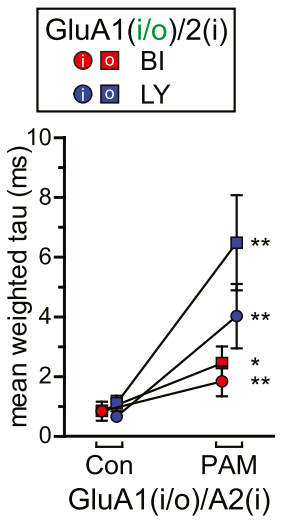

I
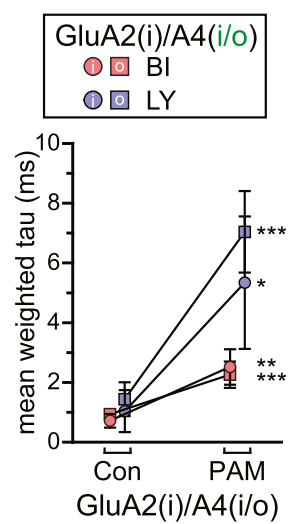

J

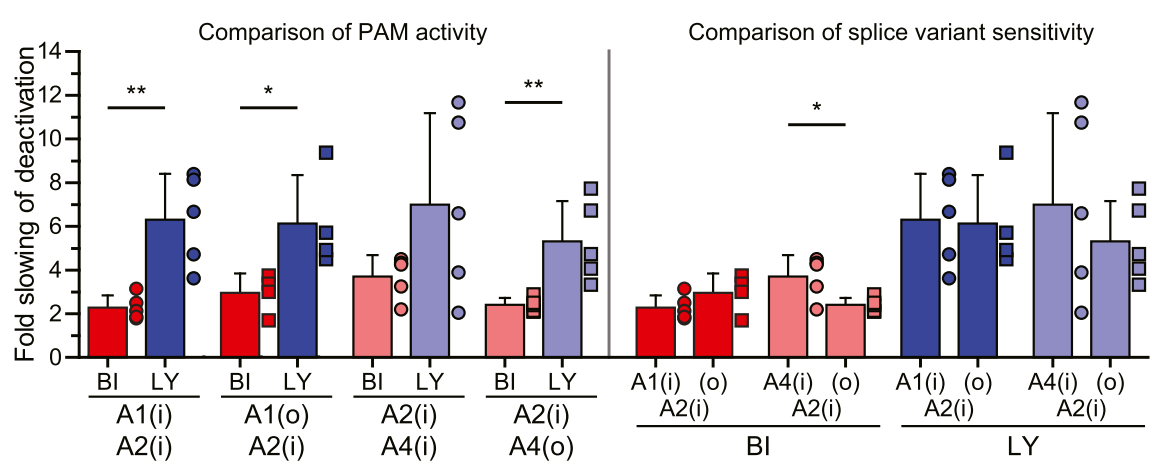

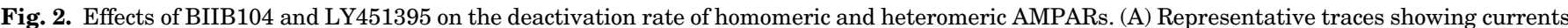

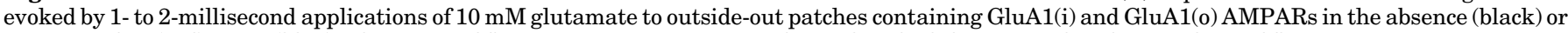

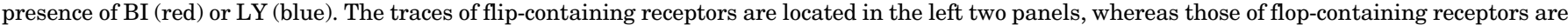

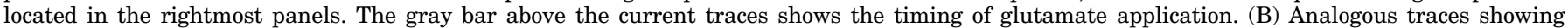

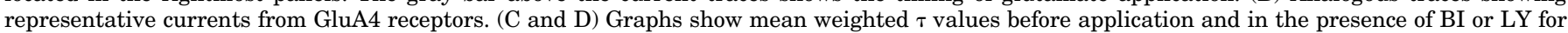


and GluA4(o) data are estimated based on incomplete curves and likely are associated with significant error. Regardless, it is apparent that BI and LY exhibit much higher potency and efficacy on the flip splice variants, consistent with previous data from human GluA2 (Shaffer et al., 2015).

BIIB104 and LY451395 Slow Deactivation of AMPARs. We next examined the effects of BIIB104 and LY451395 on receptor deactivation, a primary biophysical determinant of the time course of AMPAR-mediated EPSCs. Glutamate was applied for 1 to 2 milliseconds to outside-out patches pulled from HEK293T/17 cells expressing AMPARs. We assessed PAM actions on homomeric GluA1 and GluA4 receptors in both flip and flop splice variants as well as heteromeric GluA1/GluA2 and GluA2/GluA4 receptors (Fig. 2; Table 1). These specific heteromeric combinations were chosen because we intended to compare PAM effects on recombinant AMPARs that approximate the subunit composition of neuronal receptors at two important central synapses: those located at connections between hippocampal Schaffer collaterals and CA1 pyramidal neurons (Lu et al., 2009) and between cerebellar mossy fibers and granule cells (Martin et al., 1993).

Both PAMs slowed the deactivation rates and increased the peak current of homomeric and heteromeric AMPARs (Fig. 2; see also Table 1 for means, S.D., and the number of recordings). Representative currents evoked from GluA1(i) and GluA1(o) receptors are shown before (black) and after application of BI (red) or LY (blue) in Fig. 2A (both PAMs applied at $10 \mu \mathrm{M})$; analogous traces are shown for homomeric GluA4(i) and GluA4(o) receptors in Fig. 2B. As is apparent, LY slowed deactivation to a greater degree for each of the four types of receptors tested. Basal deactivation rates for all four homomeric receptors were rapid (mean range 0.5-1.6 milliseconds; Table 1) and consistent with previous reports (Fig. 2, C and D) (Mosbacher et al., 1994). BI slowed deactivation of homomeric GluA1(i) and GluA4(i) receptors by 4 - to 5 -fold [in the presence of BI: GluA1(i), $2.2 \pm 1.5$ milliseconds, $P=0.046$ vs. control $\tau_{\text {deact }}$; GluA4(i), $2.8 \pm 1.7$ milliseconds, $P=0.031$ ] and was less efficacious on flop-containing receptors [GluA1(o): $1.8 \pm 0.5$ milliseconds, $P=0.010$; GluA4(o): $1.8 \pm 0.5$ milliseconds, $P=$ $0.0005]$. LY slowed deactivation to a greater degree, 6- to 8fold, on both flip and flop isoforms of GluA1 and GluA4 [in the presence of LY: GluA1(i), $5.2 \pm 1.6$ milliseconds, $P=0.003$ vs. control $\tau_{\text {deact }}$; GluA4(i), $4.9 \pm 1.0$ milliseconds, $P=0.0004$; GluA1(o), $9.3 \pm 3.9$ milliseconds, $P=0.026$; GluA4(o), $6.9 \pm$ 0.3 milliseconds, $P<0.0001$ ]. The fold changes in $\tau_{\text {deact }}$ for $B I$ versus $L Y$ on each of the homomeric receptors is shown in Fig. 2E as are the comparisons of PAM activity between flip and flop isoforms of GluA1 and GluA4. These initial deactivation studies demonstrate that 1) BI exhibits differential efficacy on flip- and flop-containing homomeric AMPARs, 2) the effect of LY is roughly equivalent on the splice variants, 3) LY slows currents gated by homomeric AMPARs to a greater degree than BI, and 4) neither PAM shows receptor subunit (i.e., GluA1 vs. GluA4) selectivity.

The actions of both PAMs on heteromeric GluA1/GluA2 or GluA2/GluA4 receptors were similar to those on homomeric receptors in the preceding experiment (Fig. 2, F and G; Table 1). BI again was less efficacious, slowing deactivation by 2 - to 3 -fold in comparison with 6 - to 7 -fold observed with LY (Fig. 2, H-J). In these experiments, GluA2 was in the flip isoform for both sets of heteromeric receptors, with GluA1 (Fig. 2H) and GluA4 (Fig. 2I) in either flip or flop. The presence of the GluA2(i) isoform appeared to reduce the influence of the flip and flop isoforms in the other component subunit; neither PAM showed substantial splice isoform specificity, with the exception of a modest difference in BI activity on GluA2(i)/ GluA4(i) compared with GluA2(i)/GluA4(o) (Fig. 2J). Both PAMs modulated deactivation to a roughly equivalent degree in the two types of heteromeric receptors (GluA1/A2 or GluA2/ A4), again underscoring the absence of a discernable subunit selectivity of allosteric potentiation.

Auxiliary Subunits Profoundly Alter Allosteric Modulation of AMPARs by PAMs. Neuronal AMPARs form obligatory complexes with a diverse set of auxiliary proteins (Greger et al., 2017). How PAMs differentially modulate receptors with distinct complements of auxiliary proteins is not well understood but is relevant to their in vivo efficacy and toxicity. We therefore examined the efficacy of the two PAMs on AMPARs assembled with TARPs present in hippocampal CA1 pyramidal neurons $(\gamma 8)$ (Rouach et al., 2005) and cerebellar granule cells (Stg) (Chen et al., 2000). As in the preceding set of experiments, we first recorded from homomeric receptors (in this case, only GluA4) and then from heteromeric GluA1/GluA2 and GluA2/GluA4 receptors. The objectives were 4-fold: 1) to determine to what extent TARPs modified the efficacy of BI and LY, 2) to determine if PAM effects of Stg and $\gamma 8$ on PAM activity diverged, 3) to detect if the selectivity of PAMs for flip versus flop isoforms was altered in the presence of TARPs, and 4) to establish a set of recordings from recombinant receptors with which to compare PAM actions on synaptic currents in subsequent experiments.

Incorporation of $\mathrm{Stg}$ and $\gamma 8$ slow deactivation kinetics relative to receptors lacking the TARPs (Priel et al., 2005; Cho et al., 2007); their effect on PAM efficacy was substantial and extended to both BI and LY (Fig. 3; Table 1). Representative currents before and in the presence of PAMs are shown in Fig. 3, A and B, with the mean $\tau_{\text {deact }}$ values in the accompanying graphs on the right (Fig. 3, C and D). GluA4/ Stg receptors were profoundly slowed 40-80-fold by BI and LY [BI: GluA4(i)/Stg, $40.0 \pm 8.7$-fold; GluA4(o)/Stg, $45.7 \pm 29.1$ fold; LY: GluA4(i)/Stg, $77.8 \pm$ 49.6-fold; GluA4(o)/Stg $64.8 \pm$ 25.4; $n=5,6,5$, and 6, respectively] (Fig. 3, C and E). There was no statistical difference between the modulation by BI and LY, nor was the differential activity of BI on GluA4(i) versus GluA4(o) splice variants observed in the presence of Stg.

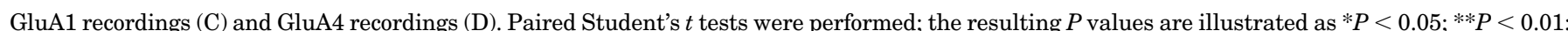

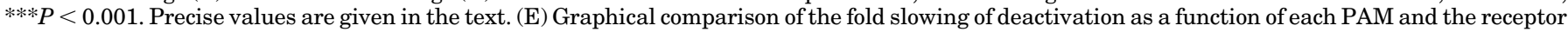

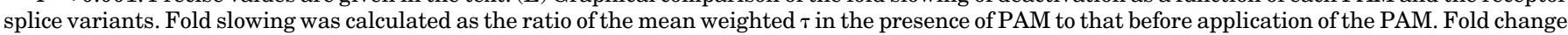

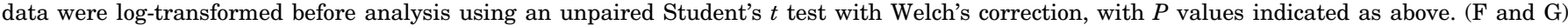

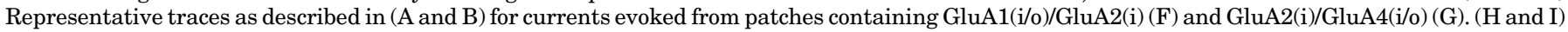

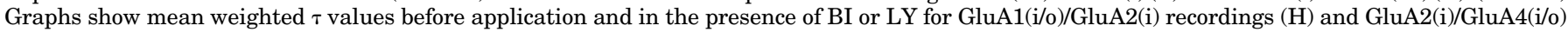
recordings (I). (J) Fold slowing of current deactivation as a function of each PAM and of splice variants.
} 
TABLE 1

Summary of BIIB104 and LY451395 modulation of amplitudes and deactivation time constants of AMPARs

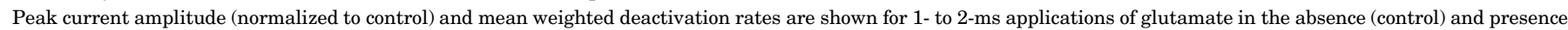

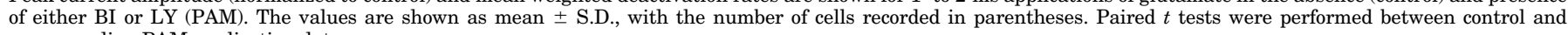
corresponding PAM application data.

\begin{tabular}{|c|c|c|c|c|c|c|c|c|}
\hline \multirow[b]{2}{*}{ Receptor } & \multicolumn{4}{|c|}{ BIIB104 } & \multicolumn{4}{|c|}{ LY451395 } \\
\hline & Normalized amplitude (\%) & $P$ value & $\tau_{\mathrm{de}(\mathrm{wtd})}(\mathrm{ms})$ & $P$ value & Normalized amplitude (\%) & $P$ value & $\tau_{\mathrm{de}(\mathrm{wtd})}(\mathrm{ms})$ & $P$ value \\
\hline GluA1(i) control & - & & $0.5 \pm 0.2$ & & - & & $0.9 \pm 0.2$ & \\
\hline GluA1(i) PAM & $204 \pm 68(5)$ & 0.044 & $2.2 \pm 1.5$ & 0.046 & $234 \pm 38(5)$ & 0.070 & $5.2 \pm 1.6$ & 0.003 \\
\hline GluA1(o) control & - & & $0.9 \pm 0.1$ & & - & & $1.2 \pm 0.1$ & \\
\hline GluA1(o) PAM & $126 \pm 12(5)$ & 0.050 & $1.8 \pm 0.5$ & 0.010 & $129 \pm 30(4)$ & 0.294 & $9.3 \pm 3.9$ & 0.026 \\
\hline GluA4(i) control & - & & $0.6 \pm 0.2$ & & - & & $0.6 \pm 0.1$ & \\
\hline GluA4(i) PAM & $227 \pm 55(5)$ & 0.002 & $2.8 \pm 1.7$ & 0.031 & $251 \pm 133(5)$ & 0.103 & $4.9 \pm 1.0$ & $<0.001$ \\
\hline GluA4(o) control & - & & $0.9 \pm 0.3$ & & - & & $0.9 \pm 0.1$ & \\
\hline GluA4(o) PAM & $121 \pm 21(5)$ & 0.219 & $1.8 \pm 0.5$ & $<0.001$ & $127 \pm 32(4)$ & 0.289 & $6.9 \pm 0.3$ & $<0.001$ \\
\hline GluA1(i)/GluA2(i) control & - & & $0.8 \pm 0.3$ & & - & & $0.7 \pm 0.1$ & \\
\hline GluA1(i)/GluA2(i) PAM & $185 \pm 29(5)$ & 0.144 & $1.8 \pm 0.5$ & 0.003 & $230 \pm 25(5)$ & 0.074 & $4.0 \pm 1.1$ & 0.003 \\
\hline GluA1(o)/GluA2(i) control & - & & $0.9 \pm 0.1$ & & - & & $1.1 \pm 0.3$ & \\
\hline GluA1(o)/GluA2(i) PAM & $129 \pm 15(4)$ & 0.125 & $2.5 \pm 0.6$ & 0.016 & $133 \pm 14(4)$ & 0.053 & $6.5 \pm 1.6$ & 0.006 \\
\hline GluA2(i)/GluA4(i) control & - & & $0.7 \pm 0.2$ & & - & & $1.0 \pm 0.7$ & \\
\hline GluA2(i)/GluA4(i) PAM & $141 \pm 60(5)$ & 0.234 & $2.5 \pm 0.6$ & 0.002 & $211 \pm 118(5)$ & 0.144 & $5.3 \pm 2.2$ & 0.015 \\
\hline GluA2(i)/GluA4(o) control & - & & $0.9 \pm 0.2$ & & - & & $1.4 \pm 0.6$ & \\
\hline GluA2(i)/GluA4(o) PAM & $142 \pm 62(5)$ & 0.116 & $2.3 \pm 0.4$ & 0.001 & $117 \pm 46(5)$ & 0.471 & $7.0 \pm 1.4$ & $<0.001$ \\
\hline GluA4(i)/Stg control & - & & $1.7 \pm 0.8$ & & - & & $1.2 \pm 0.4$ & \\
\hline GluA4(i)/Stg PAM & $216 \pm 88(5)$ & 0.054 & $71.6 \pm 46.7$ & 0.027 & $225 \pm 92(5)$ & 0.133 & $90.2 \pm 58.0$ & 0.027 \\
\hline GluA4(o)/Stg control & - & & $1.6 \pm 0.5$ & & - & & $1.4 \pm 0.4$ & \\
\hline GluA4(o)/Stg PAM & $129 \pm 43(6)$ & 0.968 & $74.5 \pm 60.5$ & 0.031 & $125 \pm 22(6)$ & 0.090 & $97.4 \pm 69.4$ & 0.019 \\
\hline GluA4(i) $/ \gamma 8$ control & - & & $1.6 \pm 0.6$ & & - & & $1.0 \pm 0.2$ & \\
\hline GluA4(i)/ $/ 8$ PAM & $275 \pm 137(5)$ & 0.018 & $11.1 \pm 9.2$ & 0.077 & $222 \pm 50(4)$ & 0.090 & $21.7 \pm 7.3$ & 0.010 \\
\hline GluA4(o) $/ \gamma 8$ control & - & & $2.2 \pm 1.0$ & & - & & $2.6 \pm 0.8$ & \\
\hline GluA4 $(0) / \gamma 8$ PAM & $155 \pm 60(6)$ & 0.191 & $23.1 \pm 18.9$ & 0.038 & $178 \pm 56(6)$ & 0.050 & $78.1 \pm 52.6$ & 0.016 \\
\hline GluA1(i)/GluA2(i) $/ \gamma 8$ control & - & & $1.7 \pm 1.0$ & & - & & $1.6 \pm 0.9$ & \\
\hline GluA1(i)/GluA2(i)/ $\gamma 8$ PAM & $163 \pm 40(6)$ & 0.025 & $3.2 \pm 1.5$ & 0.067 & $174 \pm 98(6)$ & 0.200 & $10.8 \pm 3.2$ & $<0.001$ \\
\hline GluA1(o)/GluA2(i)/ $/ \gamma 8$ control & - & & $2.1 \pm 1.1$ & & - & & $2.0 \pm 0.6$ & \\
\hline GluA1(o)/GluA2(i)/ $\gamma 8$ PAM & $131 \pm 42(7)$ & 0.692 & $7.7 \pm 5.7$ & 0.020 & $158 \pm 44(9)$ & 0.041 & $23.6 \pm 20.2(7)$ & 0.030 \\
\hline GluA2(i)/GluA4(i)/Stg control & - & & $3.4 \pm 1.6$ & & - & & $2.5 \pm 1.0$ & \\
\hline GluA2(i)/GluA4(i)/Stg PAM & $113 \pm 25(7)$ & 0.452 & $145.4 \pm 103.1$ & 0.019 & $179 \pm 45(6)$ & 0.104 & $54.1 \pm 35.7$ & 0.017 \\
\hline GluA2(i)/GluA4(o)/Stg control & - & & $4.5 \pm 3.5$ & & - & & $2.6 \pm 1.2$ & \\
\hline GluA2(i)/GluA4(o)/Stg PAM & $98 \pm 18(6)$ & 0.591 & $119.0 \pm 92.3$ & 0.027 & $137 \pm 24(5)$ & 0.013 & $81.4 \pm 51.6$ & 0.027 \\
\hline
\end{tabular}

GluA4 receptors containing $\gamma 8$ were slowed to a lesser extent than those with $\mathrm{Stg}$, as the representative traces in Fig. 3B illustrate. BI was less efficacious than LY in modulating deactivation of $\gamma 8$-containing receptors (Fig. 3 , $\mathrm{D}$ and E; Table 1). GluA4(i)/ $\gamma 8$ and GluA4(o)/ $/ \gamma 8$ had basal deactivation rates that were modestly slower than their TARP-less counterparts (Table 1), and these currents were slowed to a similar degree by BI [BI: GluA4(i) $/ \gamma 8,6.9 \pm 5.4-$ fold, $n=5$; GluA4(o) $/ \gamma 8,10.1 \pm 6.1$-fold, $n=6$ ]. LY was more efficacious than BI in slowing the deactivation of both receptor isoforms [LY: GluA4(i)/ $/ \gamma 8,21.3 \pm 4.6$-fold, $n=4$; GluA4(o) $/ \gamma 8,29.3 \pm 15.3$-fold, $n=6$ ]. As is apparent from the data, neither BI nor LY exhibited differential activity on flip versus flop isoforms when complexed with $\gamma 8$. Two points are worth noting regarding the mean weighted $\tau$ data shown in Fig. 3D. First, the slowing of GluA4(i)/ $\gamma 8$ by BI (pink circles) did not achieve statistical significance (control, $1.6 \pm 0.6$ milliseconds; in BI, $11.1 \pm 9.2$ milliseconds, $n=5 ; P=0.077$ ), which we attribute to a high degree of variability in the response of currents to the PAM. Second, the effect of LY on GluA4(o) $/ \gamma 8$ currents (pale blue squares) appears to be greater than the other three experimental conditions in that it slowed currents to a mean of $78 \pm 52.6$ milliseconds; however, the fold change induced by this PAM was only 29.3-fold, as noted above, because deactivation of the pre-PAM currents was comparatively slow (2.6 \pm 0.8 milliseconds, $n=6$ ). In summary, these data demonstrate that Stg incorporation greatly enhances modulation of AMPARs by both PAMs independent of flip/flop splice isoform and that LY is more efficacious than BI at slowing decay of $\gamma 8$ containing receptors.

In our final set of experiments with recombinant receptors, we examined how the incorporation of TARPs into heteromeric receptors alters the allosteric modulation by $\mathrm{BI}$ and $\mathrm{LY}$ (Fig. 4; Table 1). As described before, we selected two populations of heteromeric receptors likely to approximate those AMPARs found at either hippocampal CA1 pyramidal cell synapses (GluA1/GluA2/ $\gamma 8$ ) or cerebellar granule neurons (GluA2/GluA4/Stg) (Fig. 4, A and B). We also tested the flip/ flop splice isoforms of GluA1 and GluA4, respectively; GluA2 was in the flip isoform for all the experiments. GluA1/GluA2/ $\gamma 8$ receptors responded to the PAM in a qualitatively similar manner as homomeric GluA4 receptors in the preceding experiments. BI did not slow deactivation of GluA1(i)/ GluA2(i) $/ \gamma 8$ receptors to a significant degree despite all but one of the recordings exhibiting some PAM effect $\left(\tau_{\text {deact }}\right.$ control, $1.7 \pm 1.0$ milliseconds; in $\mathrm{BI}, 3.2 \pm 1.5$ milliseconds, $P=0.067$ ) (Fig. 4C; Table 1). GluA1(o)/GluA2(i) $/ \gamma 8$ receptors were modulated modestly by $\mathrm{BI}$, and heteromeric receptors with both GluA1 splice isoforms were significantly slowed by LY (Fig. 4C). The presence of a flip or flop isoform again did not appear to shape the response to either PAM, but there was a clear difference in the efficacy of BI and LY in slowing deactivation of GluA1/GluA2/ $\gamma 8$ receptors [BI: GluA1(i)/ GluA2(i)/ $\gamma 8,2.4 \pm 1.1$-fold, $n=6$; GluA1(o)/GluA2(i) $/ \gamma 8,3.6$ \pm 0.9-fold, $n=7$; LY: GluA1(i)/GluA2(i)/ $\gamma 8,8.6 \pm 4.5$-fold, $n=$ 6; GluA1(o)/GluA2(i)/ $/ \gamma 8,12.5 \pm$ 9.8-fold, $n=7$ ] (Fig. 4E). As 

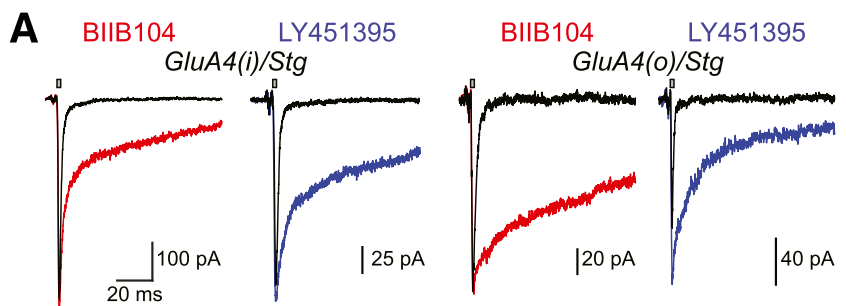

C
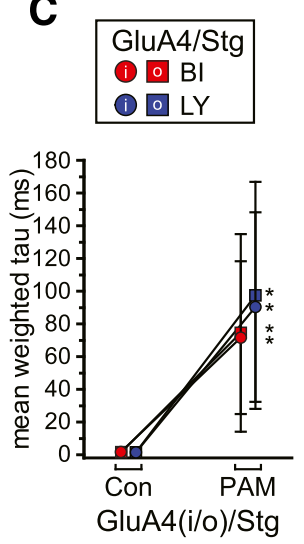

GluA4(i/o)/Stg
D
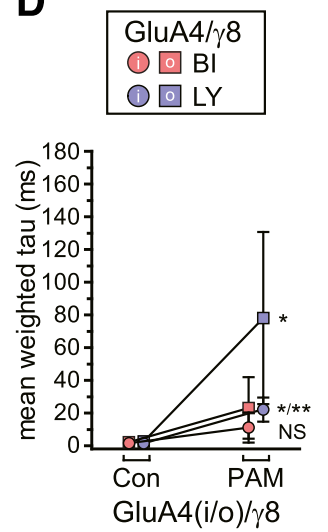

GluA4(i/o)/ $/ 8$

E
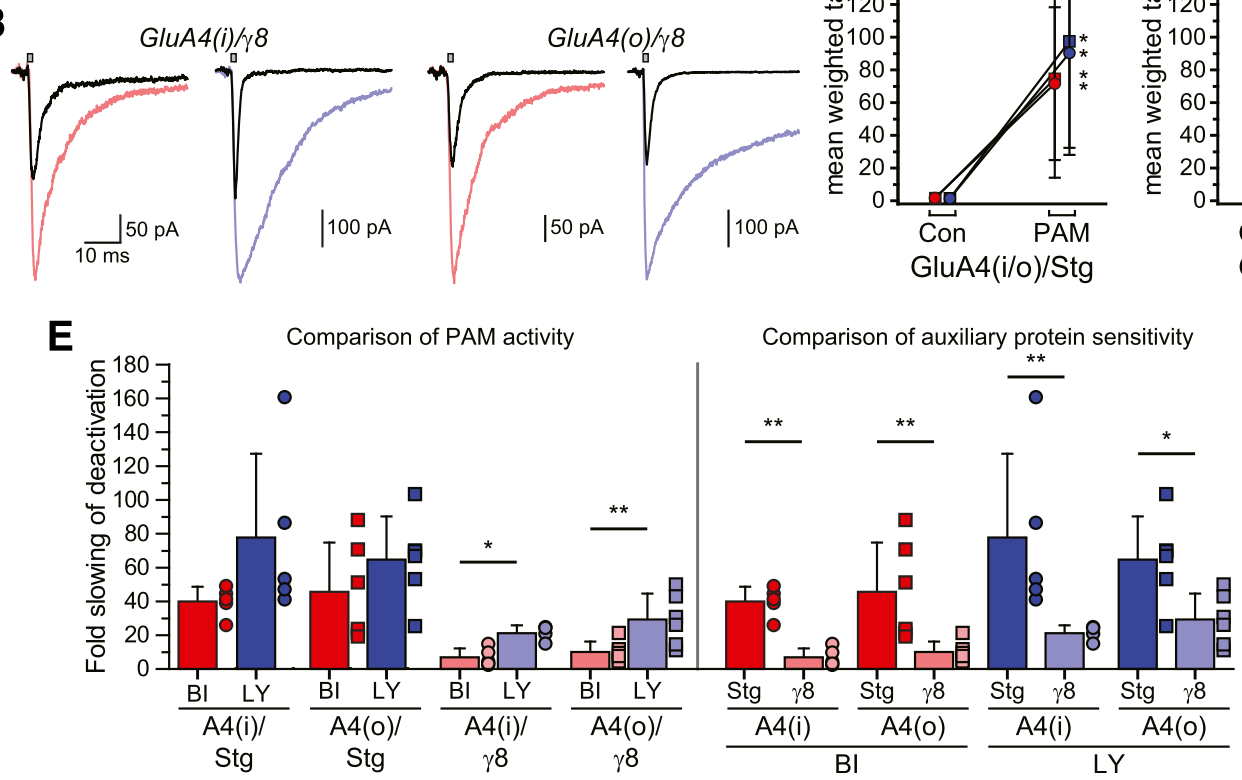

Fig. 3. Effects of BIIB104 and LY451395 on the deactivation rate of GluA4 receptors containing the Stg/ $\gamma 2$ or $\gamma 8$ TARPs. (A) Representative traces showing currents evoked by 1- to 2-millisecond applications of $10 \mathrm{mM}$ glutamate to outside-out patches containing GluA4(i) and GluA1(o) AMPARs assembled with Stg in the absence (black) or presence of BI (red) or LY (blue). The traces of flip-containing receptors are located in the left two panels, whereas those of flop-containing receptors are located in the rightmost panels. The gray bar above the current traces shows the timing of glutamate application. (B) Analogous traces showing representative currents from GluA4 receptors containing the $\gamma 8$ TARP. (C and D) Graphs show mean weighted $\tau$ values before application and in the presence of BI or LY for GluA4/Stg recordings (C) and GluA4/ $\gamma 8$ recordings (D). Paired Student's $t$ tests were performed; the resulting $P$ values are illustrated as ${ }^{\mathrm{NS}} P>0.05$; ${ }^{*} P<0.05 ; * * P<0.01 ; * * * P<0.001$. Precise values are given in the text. (E) Graphical comparison of the fold slowing of deactivation as a function of each PAM and the receptor splice variants. Fold slowing was calculated as the ratio of the mean weighted $\tau$ in the presence of PAM to that before application of the PAM. Fold change data were log-transformed before analysis using an unpaired Student's $t$ test with Welch's correction, with $P$ values indicated as above.

the column graph indicates, a relative comparison of the PAM actions supports the conclusion that LY has a greater magnitude of effect on GluA1/GluA2/ $\gamma 8$ receptors.

This discrimination in the activity of the PAMs was not present with Stg as the incorporated TARP in the "granule celllike" receptors, however (Fig. 4, D and E). Both PAMs profoundly slowed glutamate-activated currents from GluA2/ GluA4/Stg receptors by lengthening the time constants and increasing the proportional contribution of the slower of two exponential components fit to the current decays. This resulted in weighted $\tau_{\text {deact }}$ values ranging from $\sim 50$ to 150 milliseconds in PAMs (Fig. 4D), which did not exhibit any differential efficacy in their fold slowing of decay [BI: GluA2(i)/GluA4(i)/Stg, $41.6 \pm 22.7$-fold, $n=6$; GluA2(i)/GluA4(o)/Stg, $29.2 \pm 25.5$-fold, $n=6$; LY: GluA2(i)/GluA4(i)/Stg, $24.1 \pm 15.2$-fold, $n=6$; GluA2(i)/ GluA4(o)/Stg, $36.8 \pm 31.2$-fold, $n=5$ ] (Fig. 4E; Table 1). In summary, these data show that TARPs assembly with AMPARs has differential consequences on modulation by PAMs, with Stg being a predominant determinant of both BI and LY activity.

Excitatory Synaptic Currents are Differentially Modulated by PAMs. If the two heteromeric AMPAR combinations tested in the preceding experiments do in fact model those found at the two CNS synapses, our results predict that cerebellar granule cell EPSCs should be much more sensitive to the PAMs than CA1 pyramidal cell EPSCs. We tested this prediction in voltage-clamp recordings of spontaneous and evoked EPSCs in hippocampal CA1 pyramidal cell and cerebellar granule cells. Two concentrations of the PAMs were tested, $1 \mu \mathrm{M}$ and $30 \mathrm{nM}$, which should be saturating in the first case and near the $\mathrm{EC}_{50}$ value for neuronal AMPARs (Shaffer et al., 2013, 2015).

Both PAMs slowed AMPAR-mediated EPSCs in CA1 pyramidal neurons evoked by monopolar stimulation of the stratum radiatum (Fig. 5A). At a saturating concentration, the time course of EPSC decay was significantly slowed by LY to a greater extent than $\mathrm{BI}(\mathrm{BI}$ : control, $8.3 \pm 1.0$ milliseconds; PAM, $12.2 \pm 2.8$ milliseconds, $n=8, P=0.0021$; LY: control, 9.3 \pm 1.8 milliseconds; PAM, $28.4 \pm 6.5$ milliseconds, $n=9, P<$ 0.0001 ) (Fig. 5B). The fold slowing of decay time courses were $1.5 \pm 0.3(\mathrm{BI})$ and $3.1 \pm 0.7(\mathrm{LY})(P<0.0001$ with Welch's $t$ test $)$. At the lower concentration, however, only LY slowed the evoked EPSCs (Fig. 5C). Thirty nanomolar BI did not detectably change the decay of the synaptic currents, whereas LY slowed the fitted weighted $\tau$ values from $8.0 \pm 1.1$ to $9.2 \pm 1.7$ milliseconds ( $n=8, P=0.019$ ), a fold slowing of 1.15 -fold. We did not observe any effect of either of the PAMs on paired-pulse 
A Hippocampal CA1-like

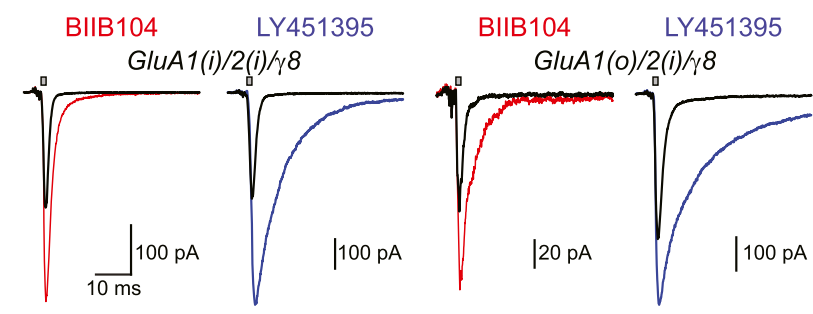

B Cerebellar granule cell-like
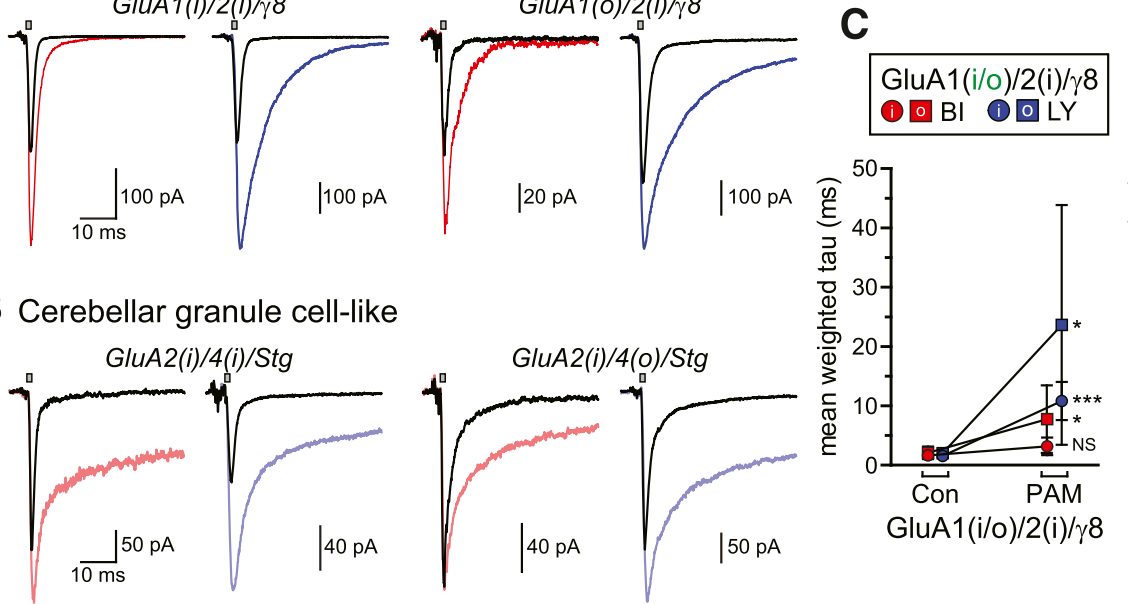

D
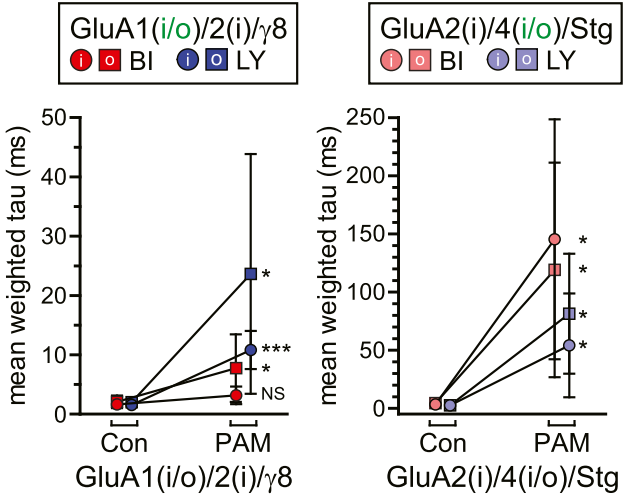

E

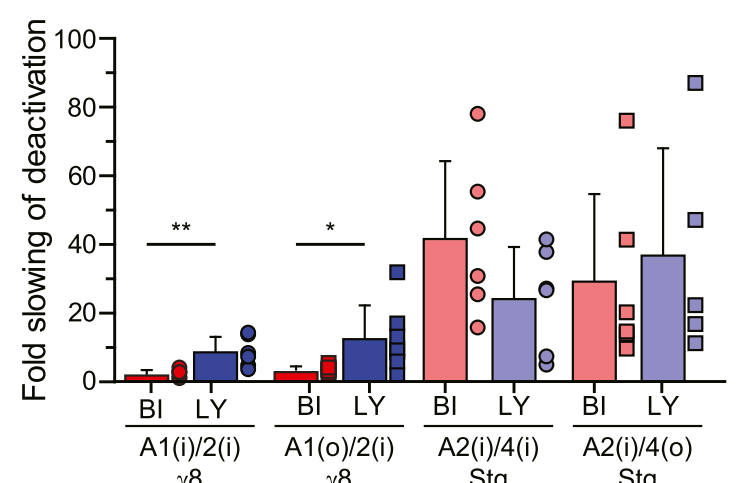

$\gamma 8$

$\gamma 8$

Stg

Stg

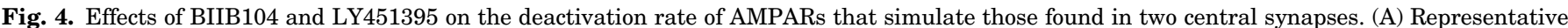

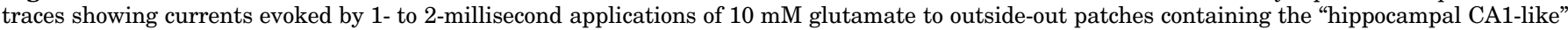

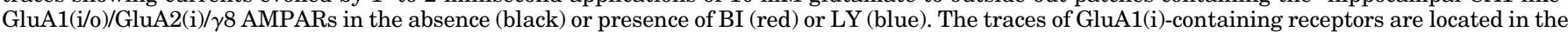

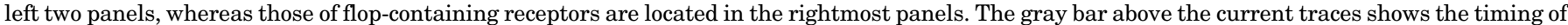

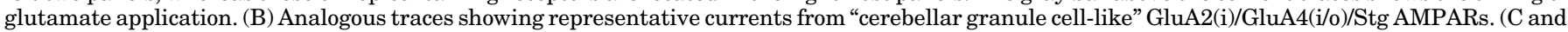

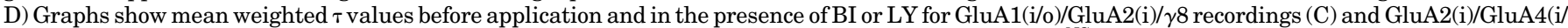

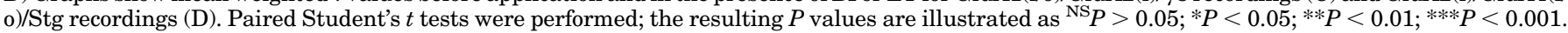

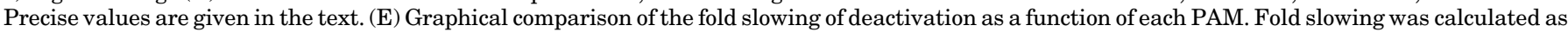

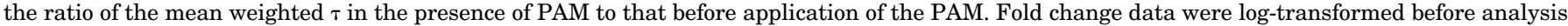
using an unpaired Student's $t$ test with Welch's correction, with $P$ values indicated as above.

facilitation of EPSCs evoked with a 40-millisecond interval (Fig. 5, D and E), suggesting that they did not alter presynaptic release probability at the concentration tested. Also, the amplitudes of the first EPSC in the pairs were not increased by PAMs (Fig. 5F), demonstrating that the primary consequence of neuronal AMPAR modulation by these PAMs is prolongation of decay kinetics.

Spontaneous EPSCs recorded from CA1 pyramidal neurons were also slowed to a greater degree by LY451395. EPSCs were recorded in the absence and presence of BI or LY $(1 \mu \mathrm{M})$ (Fig. 6A). Isolated EPSCs are shown in Fig. 6B for each condition (gray overlaid events, PAM at $1 \mu \mathrm{M}$ ) with the averaged trace shown as red (BI) or blue (LY); respective averaged controls traces are in black. The fitted decay time constant slowed to an extent similar to that observed for evoked EPSCs in the previous experiment (BI: control, $8.1 \pm$ 1.5 milliseconds; PAM, $12.6 \pm 2.4$ milliseconds, $n=12, P<$ 0.0001; LY: control 9.2 \pm 1.3 milliseconds; PAM, $21.5 \pm 4.8$ milliseconds, $n=10, P<0.0001$; Fig. $6 \mathrm{C})$. As with the evoked
EPSCs, the fold change of the weighted time constant of sEPSCs was greater with LY $(2.3 \pm 0.4$-fold $)$ compared with BI $(1.6 \pm 0.3$-fold $)(P=0.0001$ with Welch's $t$ test $)$. The mean amplitude of sEPSCs was unchanged by the PAMs (BI: control, $35 \pm 6 \mathrm{pA}$; PAM, $32 \pm 6 \mathrm{pA}, P=0.14$; LY: control, $29 \pm 5 \mathrm{pA} ; \mathrm{PAM}, 26 \pm 3 \mathrm{pA}, P=0.25$ ); the frequency of $\mathrm{sEPSC}$ also was not altered by the modulators (data not shown). At the lower concentration of $30 \mathrm{nM}$, LY had a modest effect on sEPSC decay (control, $6.9 \pm 0.9$ milliseconds; PAM, $7.7 \pm 1.3$ milliseconds, $n=9, P=0.0086)$, whereas $\mathrm{BI}$ did not alter the currents ( $n=8, P=0.96$ ) (Fig. $6 \mathrm{D}$ ). There was no statistical difference in the fold slowing of the weighted time constant. In summary, LY was the more potent and efficacious modulator of EPSCs in CA1 pyramidal neurons, consistent with its actions on recombinant GluA1/A2/ $\gamma 8$ AMPARs.

BIIB104 and LY451395 Profoundly Slow Cerebellar EPSCs. We next tested the effect of the PAMs on EPSCs at cerebellar synapses between mossy fibers and CGCs (Fig. 7). AMPARs at this synapse are composed of heteromeric GluA2/ 
A CA1 pyramidal cells
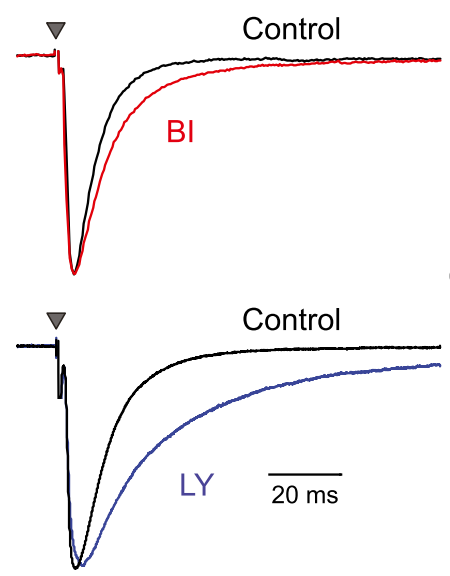

D Paired stimulation

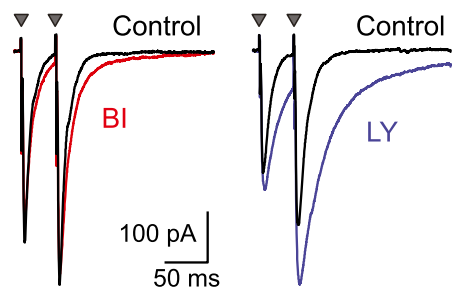

B

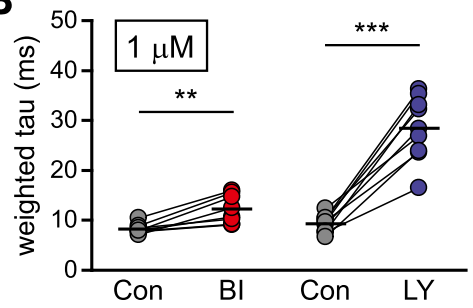

C

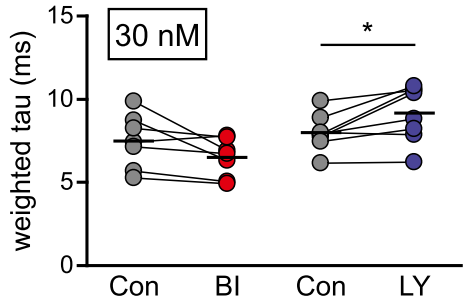

E

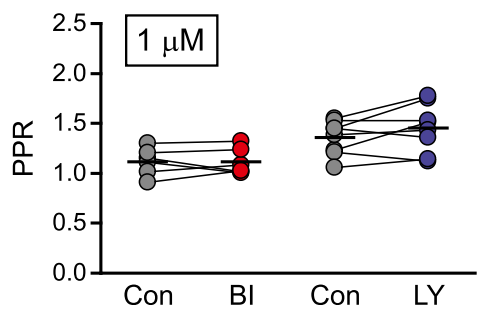

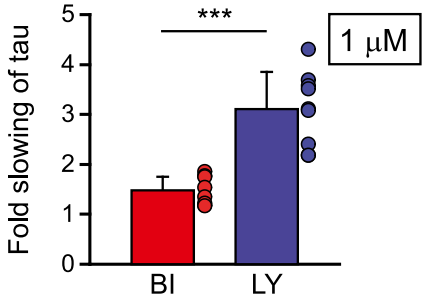

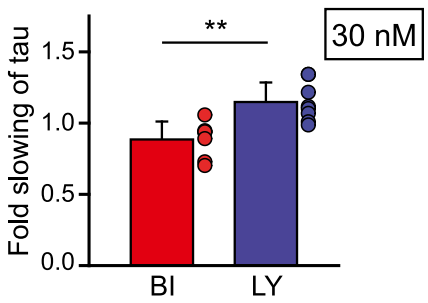

$\mathbf{F}$

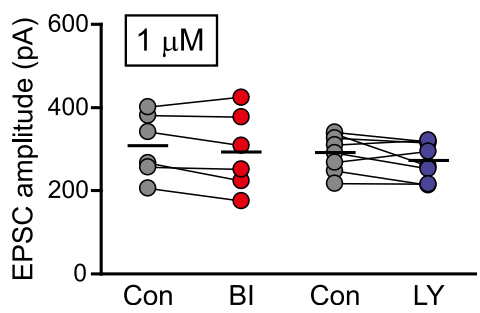

Fig. 5. Effects of BIIB104 and LY451395 on hippocampal Schaffer collateral CA1 pyramidal cell-evoked EPSCs. (A) Representative evoked EPSCs recorded in voltage clamp from CA1 pyramidal neurons in juvenile mouse brain slices before (black) and during application of $1 \mu \mathrm{M} B \mathrm{BI}$ (red) or LY (blue). Peak amplitudes of the EPSCs are normalized. (B) Weighted decay time constants of the evoked EPSCs in the absence (Con) and presence (BI or LY, 1 $\mu \mathrm{M})$ of PAMs (left). Paired Student's $t$ tests were performed; the resulting $P$ values are illustrated as $* P<0.05$; $* * P<0.01$; *** $P<0.001$. Precise values are given in the text. The graph on the right shows fold slowing of mean weighted decay time constant as a function for each PAM. Fold slowing was calculated as the ratio of the mean weighted decay time constant in the presence of PAM to that before application of the PAM. Fold change data were logtransformed before analysis using an unpaired Student's $t$ test with Welch's correction, with $P$ values indicated as above. (C) Analogous mean weighted decay time constant and fold change data for $30 \mathrm{nM}$ application of PAMs. (D) Representative pairs of evoked EPSCs before (black) and during application of $1 \mu \mathrm{M}$ BI (red) or LY (blue). (E) Paired-pulse ratios with an interval of 40 milliseconds are shown in the absence (Con) and presence (BI or LY, $1 \mu \mathrm{M})$ of PAMs. (F) EPSC amplitudes are shown in the absence (Con) and presence (BI or LY, $1 \mu \mathrm{M}$ ) of PAMs. Paired Student's $t$ tests indicated $P>0.05$ for both PPR and mean EPSC amplitude.

GluA4 and Stg (Black, 2005; Yamazaki et al., 2010). As is evident in the representative traces shown in Fig. 7A, both LY and BI dramatically slowed CGC EPSCs evoked by local stimulation of the granule cell layer when bath applied at $1 \mu \mathrm{M}$ (BI: control, $4.0 \pm 1.3$ milliseconds; PAM, $20.0 \pm 7.5$ milliseconds, $n=6, P=0.002$; LY: control, $4.7 \pm 1.1$ milliseconds; PAM, $63.4 \pm 19.2$ milliseconds, $n=6, P=$ 0.0006) (Fig. 7B). LY therefore slowed the EPSC decay by a much greater degree than BI (BI: $5.1 \pm 1.3$-fold; LY: $13.4 \pm$ 3.3 -fold, $P=0.0008$, with Welch's $t$ test, Fig. 7B). As was the case for CA1 EPSCs, the lower concentration (30 nM) of LY slowed CGC EPSCs, whereas BI did not have a detectable effect on the time course of decay, a distinction that was reflected in a difference in the fold change in the fitted time constant (BI: $1.2 \pm 0.3$-fold; LY: $1.5 \pm 0.2$-fold, $P=0.052$, Fig. 7C). Neither PAM appreciably altered the PPR (Fig. 7, D and $\mathrm{E}$ ), again suggesting that they did not alter presynaptic release of glutamate. LY did increase the amplitude of the first EPSC in the paired recordings to a small degree $(122 \%, P=$ 0.01; Fig. 7F).

Spontaneous EPSCs in CGCs also were slowed by both PAMs. LY again exhibited a greater effect on the decay of sEPSCs at the two concentrations tested, which is evident in the representative traces in Fig. 8A and the isolated sEPSCs (gray traces) and their respective averaged events in Fig. 8B. Quantification of the mean weighted $\tau$ from the fitted decays show that both BI and LY slowed decay of the synaptic currents when bath applied at $1 \mu \mathrm{M}$ (BI: control, $1.4 \pm 0.4$ milliseconds; PAM, $6.5 \pm 2.7$ milliseconds, $n=6, P=0.0062$; LY: control, $1.5 \pm 0.7$ milliseconds; PAM, $12.9 \pm 6.6$ milliseconds, $n=7, P=0.0029$ ) (Fig. $8 \mathrm{C}$ ), yielding fold-slowing values of $4.7 \pm 2.3$-fold $(\mathrm{BI})$ and $8.6 \pm 3.4$-fold $(\mathrm{LY})(P=0.035$ with Welch's $t$ test). LY, but not BI, increased the amplitude of CGC sEPSCs at this concentration (BI: control, $20.7 \pm 5.8 \mathrm{pA}$; PAM, $21.5 \pm 6.4$ pA, $P=0.67$; LY: $16.5 \pm 3.2$ pA; PAM: $21.7 \pm$ $3.6 \mathrm{pA}, P=0.023)$. At a lower concentration (30 nM), LY slowed sEPSC decay (control, $1.3 \pm 0.4$ milliseconds; PAM, 3.0 \pm 1.6 milliseconds; $n=6, P=0.037$ ), whereas $\mathrm{BI}$ did not have a detectable effect (Fig. 8D), which resulted in a greater proportional effect of LY on the decay of synaptic currents (BI: $1.0- \pm$ 0.2-fold; LY: $2.2- \pm 1.0$-fold, $P=0.023$, with Welch's $t$ test).

In summary, these data demonstrate that both PAMs exhibited greater modulatory actions on CGC EPSCs than on the CA1 EPSCs ( $P<0.001$, respectively), with LY451395 being more potent than BIIB104 for both types of synaptic AMPARs. These data are therefore consistent with the predominant role of TARP incorporation in shaping the 


\section{A CA1 pyramidal cell spontaneous EPSCs}
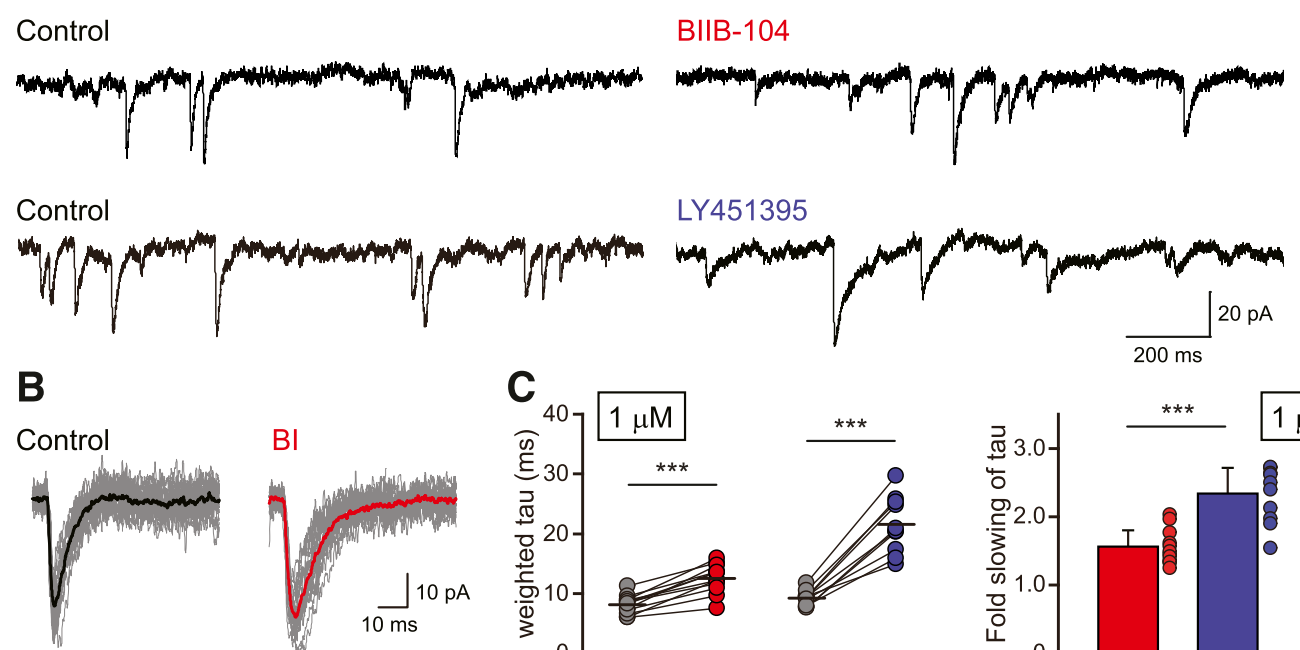

\section{LY451395}
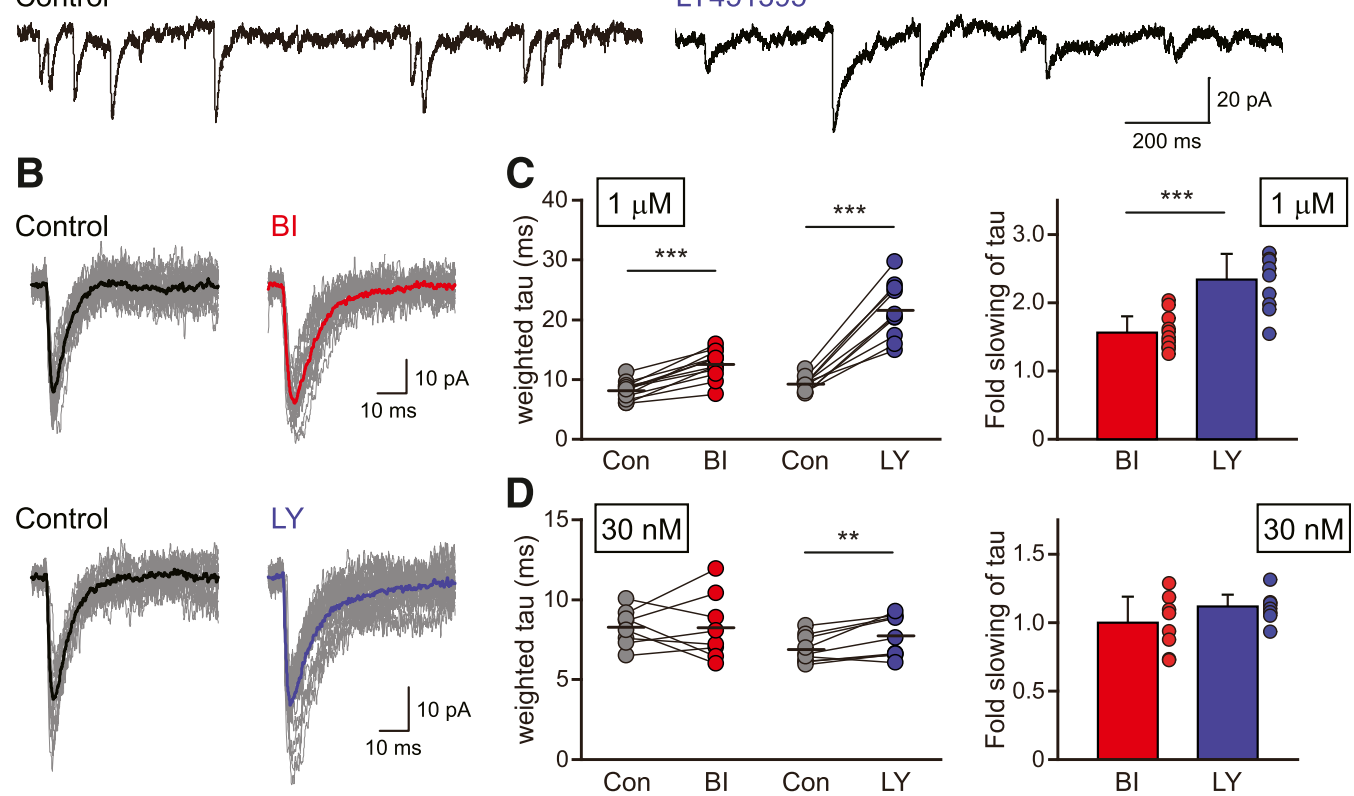

Fig. 6. Effects of BIIB104 and LY451395 on hippocampal CA1 pyramidal cell spontaneous EPSCs. (A) Representative traces of spontaneous EPSCs recorded in voltage clamp from CA1 pyramidal neurons in juvenile mouse brain slices before (black) and during application of $1 \mu \mathrm{M}$ BI (red, top right) or LY (blue, bottom right). (B) Superimposed spontaneous EPSCs (gray) with the mean trace before application of PAM (control, black) and in the presence of $\mathrm{BI}$ (red) or LY (blue). (C) Weighted decay time constants of the spontaneous EPSCs in the absence (Con) and presence (BI or LY, $1 \mu M$ ) of PAMs (left). The graph on the right shows fold slowing of mean weighted decay time constant as a function for each PAM. Fold slowing and statistical comparisons are as in Figure 5. (D) Analogous mean weighted decay time constant and fold change data for $30 \mathrm{nM}$ application of PAMs. ${ }^{* *} P<0.01 ; * * * P<0.001$.

response to PAMs that we observed in studies with recombinant AMPARs.

\section{Discussion}

In this study, we examined whether BIIB104 and LY451395 exhibited subunit-specific modulation of the AMPAR subunits, splicing variants, and TARPs in recordings from recombinant and neuronal receptors. Our primary objective was to compare how the PAMs differentially altered deactivation of glutamate-evoked currents and to what extent their activity on recombinant receptors predicted that on synaptic currents. The results showed that both BI and LY profoundly slowed the deactivation of AMPARs incorporating the Stg auxiliary subunit. Varying AMPAR subunit compositions had very little impact on relative PAM efficacy, whereas flip/flop splice variation produced the expected differential level of allosteric modulation of desensitization but had substantially less of an impact on receptor deactivation. Both PAMs also slowed decay of currents elicited from $\gamma 8$-containing AMPARs to a lesser degree than those containing Stg. The relative efficacy of the PAMs on $\gamma 8$ - and Stg-containing AMPARs was consistent with the differential slowing of decay kinetics of AMPAR-mediated EPSCs at hippocampal Schaffer collateral versus cerebellar granule cell synapses; that is, Schaffer collateral CA1 pyramidal cell synapses were slowed to a lesser degree by the PAMs as compared with their actions on cerebellar mossy fiber granule cell EPSCs.

Splice variation at the flip/flop site strongly influenced efficacy of both BIIB104 and LY451395 with respect to desensitization but not deactivation of the receptors. The effects of BI and LY on the flip variant in the desensitization process were over 10 - and 5 -times higher than the flop variant AMPAR subunits, respectively. These results were consistent with previous studies on selectivity of BI (Shaffer et al., 2015), as well as the sulfonamides LY392098 and LY404187 (Miu et al., 2001), on the function of homomeric GluA2 receptors composed of either flip or flop subunits. The flip/flop splice domain comprises, in part, the binding site for the PAMs (Shaffer et al., 2013) and is a key determinant of receptor desensitization (Mosbacher et al., 1994). In contrast, the impact of flip/flop splicing on deactivation of glutamateevoked currents was more subtle and differed between the two PAMs. BI exhibited greater efficacy on homomeric GluA1(i) and -4(i) receptors compared with their flop equivalents, whereas LY did not discriminate (Fig. 2). The slightly dominant selectivity of BI for flip-containing subunits can be attributed to interaction between its constituent cyano moiety and the polar side chain of serine 754 within the flip splice cassette (Shaffer et al., 2015). The flip/flop discrimination by $\mathrm{BI}$ is less apparent in receptors containing a mixture of subunits with flip/flip versus flip/flop (Fig. 2, F-J), which suggests that in vivo alternate splicing in this ligand-binding 


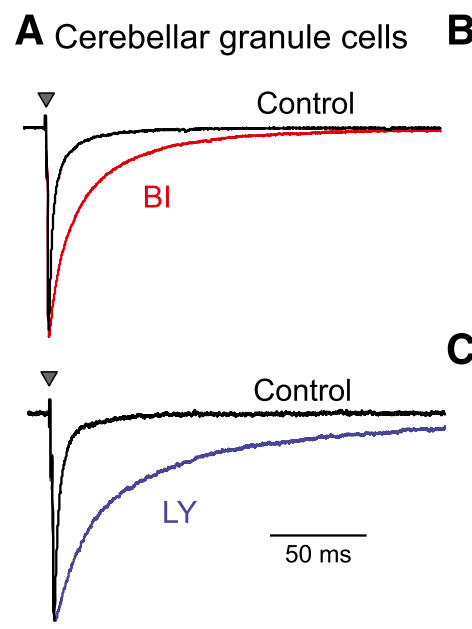

D Paired stimulation

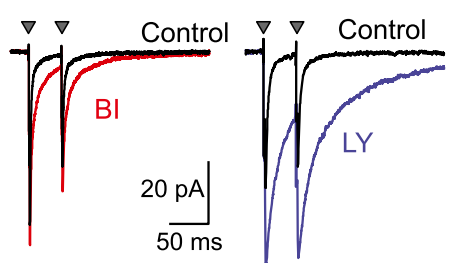

B

\section{c}
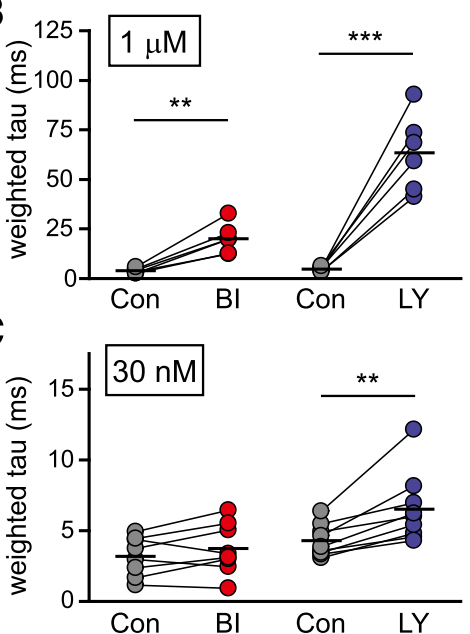

$\mathrm{E}$

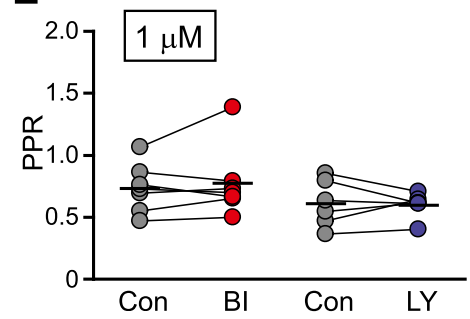

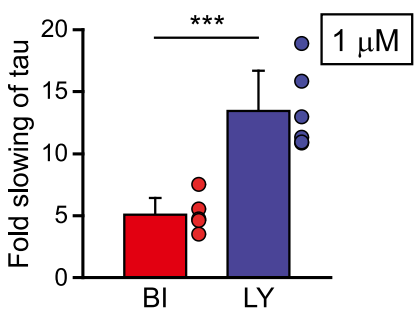

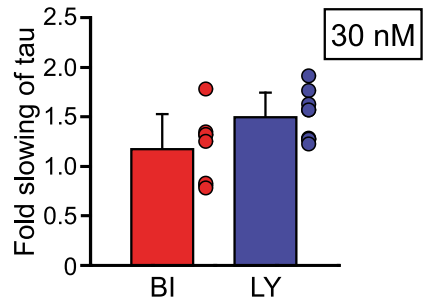

$\mathbf{F}$

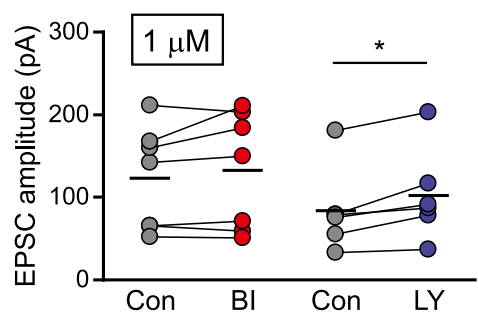

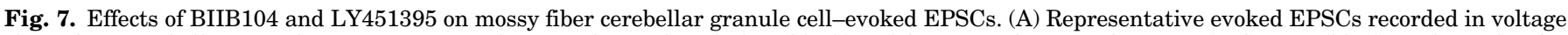

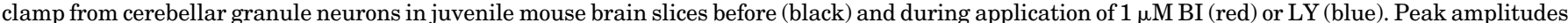

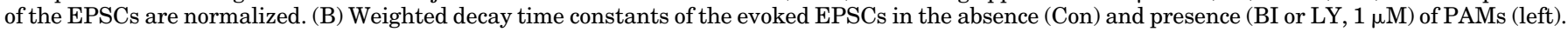

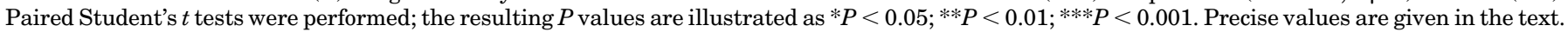

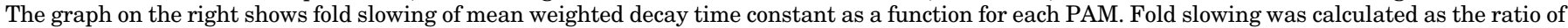

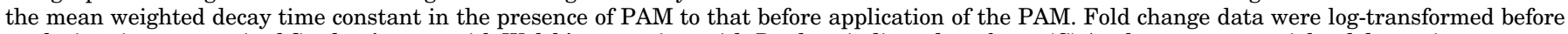

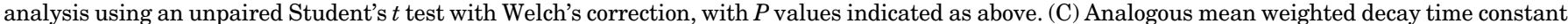

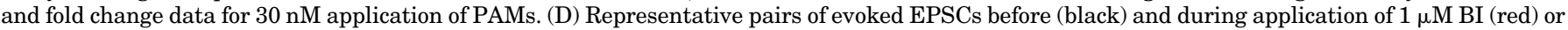

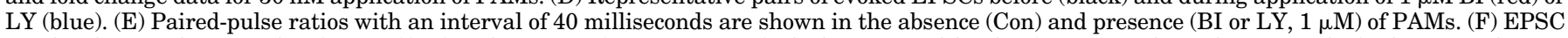

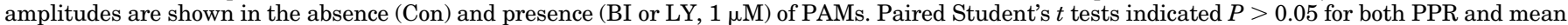
EPSC amplitude.

domain (LBD) cassette is unlikely to play a substantial role in shaping responses of single synaptic AMPARs to modulation by either PAM. Our data do not exclude the possibility, however, that the flip/flop domain could play a major role in how synaptic potentials respond to higher-frequency stimuli in the presence of PAMs because the rate of recovery from desensitization, modification of gating by TARPs, and other molecular aspects of channel function are acutely shaped by splice variation (Dawe et al., 2019).

BIIB104 and LY451395 also exhibited little selectivity between AMPARs with distinct subunit compositions (Fig. 2; Table 1). Other sulfonamides (LY392098 and LY404187), in contrast, were more than 8-fold selective for homomeric GluA4(i) and GluA2(i) receptors compared with GluA1(i)containing receptors (Miu et al., 2001). This lack of subunitdependent PAM selectivity is analogous to the biophysical properties of the $(R, R)$-2a biarylpropylsulfonamide (Kaae et al., 2007); $(R, R)-2 \mathrm{a}$ is both structurally similar to LY451395 and bridges symmetrical PAM binding pockets in the AMPA receptor LBD dimer interface analogous to BIIB104 (Kaae et al., 2007; Shaffer et al., 2015). We infer from these observations that any regional specificity in PAM activity will be shaped to a minimal degree by the stoichiometry of AMPARs, which differs across regions of the CNS (Hashimoto et al., 1999; Black, 2005) and within specific types of neurons (Coombs and Cull-Candy, 2009); rather, neuronal and regional variation in $\mathrm{BI}$ and $\mathrm{LY}$ efficacy will arise predominantly from the auxiliary proteins associated with distinct populations of AMPARs.

The conclusion that auxiliary proteins will play a primary role in shaping the response to $\mathrm{BI}$ and $\mathrm{LY}$ is derived from experiments with two TARPs: $\gamma 8$ and Stg. The deactivation time course of glutamate-evoked currents from Stg-containing AMPARs was slowed 40 -fold by both PAMs (Figs. 3 and 4). The efficacies of BI and LY are substantively greater than that of the canonical benzothiadiazide modulator cyclothiazide, which slows deactivation of recombinant GluA1/Stg receptors by $\sim 5$-fold (Tomita et al., 2006). This difference in relative modulatory actions could arise from greater accessibility or affinity for their binding sites in the dimer interface domains of AMPAR subunits that are complexed with TARPs. TARPs and other auxiliary proteins associate with AMPA receptors in the membrane domains, with their extracellular domains further interacting with gating linkers and the lower face of the D2 lobe of the LBD (Cais et al., 2014; Chen et al., 2017; Riva et al., 2017; Twomey et al., 2017). The differential efficacy of the PAMs on receptors with auxiliary proteins might therefore arise from subtle distinctions in the stabilization of LBD dimer interfaces by Stg or other TARPs, although a comparison between cryo-EM structures of largely intact 
A Cerebellar granule cell spontaneous EPSCs

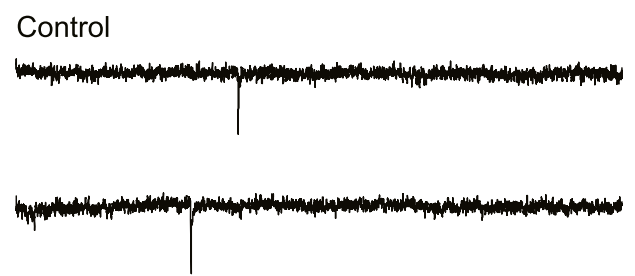

BIIB104

Control
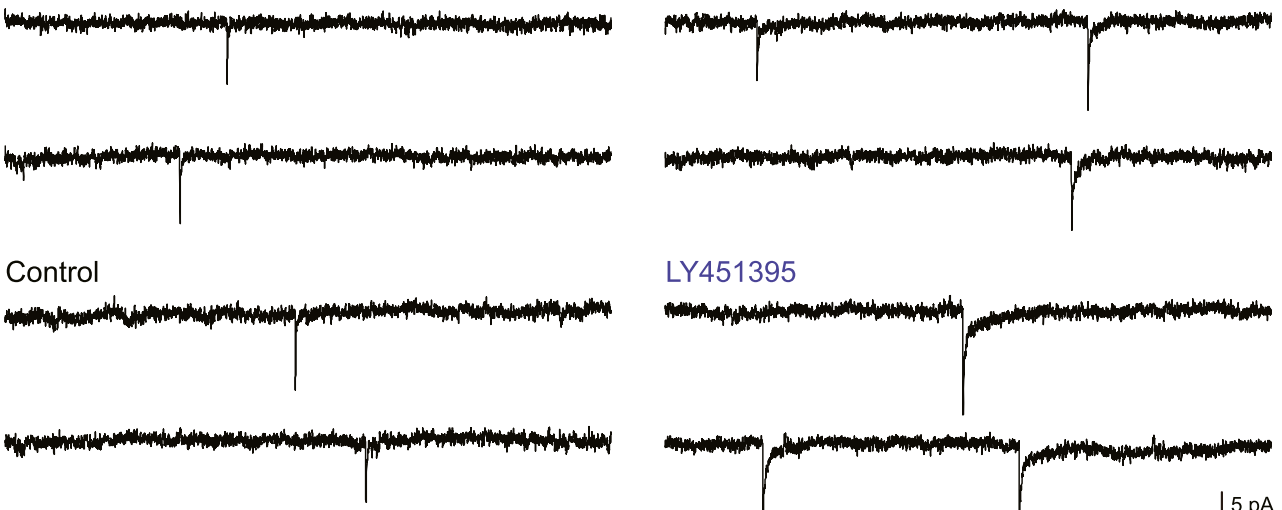

B
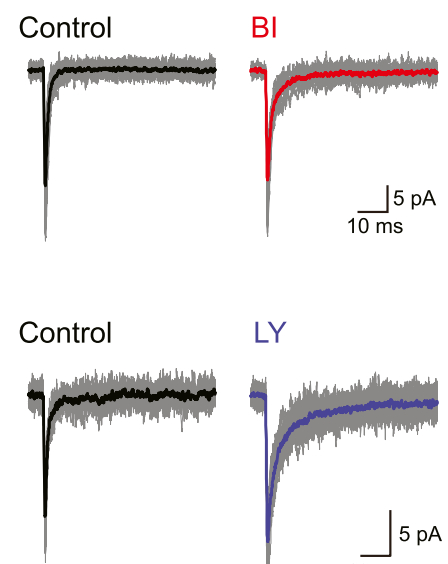

LY

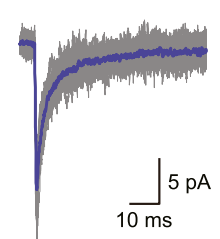

C
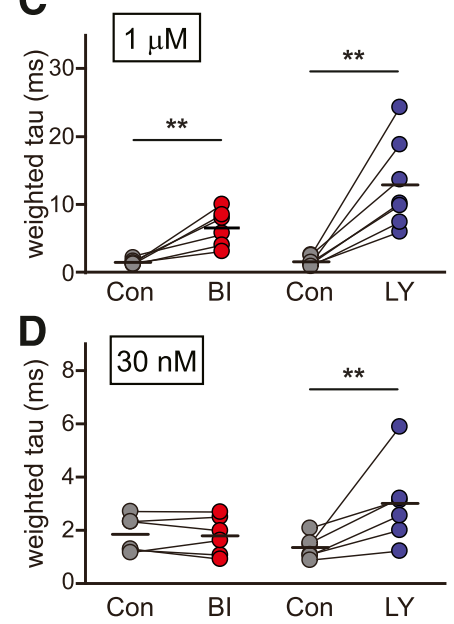

LY451395

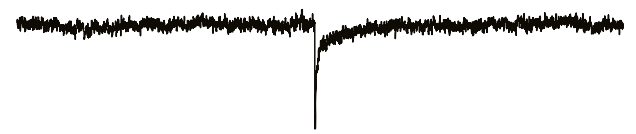

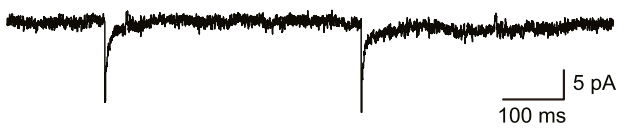

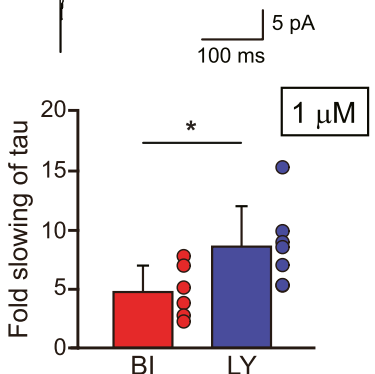

Fig. 8. Effects of BIIB104 and LY451395 on cerebellar granule cell spontaneous EPSCs. (A) Representative traces of spontaneous EPSCs recorded in voltage clamp from cerebellar granule neurons in juvenile mouse brain slices before (black) and during application of $1 \mu \mathrm{M}$ BI (red, top right) or LY (blue, bottom right). (B) Superimposed spontaneous EPSCs (gray) with the mean trace before application of PAM (Control, black) and in the presence of BI (red) or LY (blue). (C) Weighted decay time constants of the spontaneous EPSCs in the absence (Con) and presence (BI or LY, $1 \mu \mathrm{M}$ ) of PAMs (left). The graph on the right shows fold slowing of mean weighted decay time constant as a function for each PAM. Fold slowing and statistical comparisons are as in Figure 7 . (D) Analogous mean weighted decay time constant and fold change data for $30 \mathrm{nM}$ application of PAMs. ${ }^{*} P<0.05 ; * * P<0.01$; $* * * P<0.001$.

GluA2 receptors in complex with Stg and the biarylpropylsulfonamide PAM $(R, R)-2 \mathrm{~b}$ and isolated LBD structures lacking both TARPs and PAMs did not reveal marked differences in LBD structure or activation-associated clamshell closure (Chen et al., 2017). Further structural studies of AMPARs incorporating Stg with PAMs will likely provide valuable insights.

One principle objective of the current study was to compare the actions of the two PAMs at two central excitatory synapses and determine if differential efficacy could be accounted for by molecular properties of the underlying AMPARs. We found that the decay time constant of EPSCs at cerebellar mossy fiber granular cell synapses was prolonged to a greater degree by both PAMs compared with Schaffer collateral CA1 pyramidal cell EPSCs, which paralleled the outcomes in our comparative study of recombinant AMPARs complexed with the Stg or $\gamma 8$ auxiliary proteins. Modulation of native AMPARs was not perfectly recapitulated by the recombinant GluA2/GluA4/Stg receptors, however; most notably, LY slowed cerebellar EPSCs to a $\sim 3$-fold greater degree than BI, whereas the PAMs were extremely and equivalently efficacious on recombinant receptors containing Stg (Figs. 4 and 7), potentiating the decay of glutamate-evoked currents by 20-40-fold. It is possible that cerebellar granule cell EPSCs are slowed to a lesser degree than recombinant receptors by both PAMs because of the presence of AMPARs with other TARP isoforms in addition to Stg (Coombs and Cull-Candy, 2009). Alternatively, synaptic AMPARs might contain a subsaturating complement of Stg, $\gamma 8$, or other associated auxiliary proteins, which titrates their modulatory effects on receptor gating (Milstein et al., 2007).

The substantial prolongation of the cerebellar synaptic currents by both PAMs is consistent with the known motor side effects of high-impact PAMs at higher exposures (Zasadny et al., 2009; Shaffer et al., 2013, 2015) and could potentially precipitate Purkinje cell toxicity that occurs when AMPARs are overactivated (Garthwaite and Garthwaite, 1991; Brorson et al., 1995). Though BIIB104 exhibits a clear cross-species, dose-dependent engagement of cerebellar processes (i.e., increased cGMP, motor dysfunction, and FDG uptake), no evidence of Purkinje cell toxicity has been reported (Shaffer et al., 2015), and the drug has been safe and welltolerated in humans (Zasadny et al., 2009; Bednar et al., 2015). Procognitive activity occurs at nanomolar free drug 
concentrations (Shaffer et al., 2015; Ranganathan et al., 2017), with a projected therapeutic index of $\sim 37$ for self-limiting tremors in humans (Shaffer et al., 2015). LY, conversely, had preclinical "toxicologic issues" that limited its Phase 2 dosing to $1 / 5$ to $1 / 15$ of the maximum tolerated dose in patients with Alzheimer disease (Chappell et al., 2007); LY did not exhibit efficacy in either study, possibly because of the dosing limitation. Such clinically imposed dose-caps are often due to nonclinically monitorable serious adverse events, which, in this case, might have been due to an AMPAR-mediated excitotoxicity such as Purkinje cell death. To what extent these differential adverse outcomes are related to the greater in vitro efficacy reported herein of LY compared with BI on synaptic currents in cerebellum remains unclear.

In conclusion, we have identified TARP auxiliary proteins as a primary determinant of recombinant and native AMPAR modulation by two structurally related high-impact allosteric modulators. It is possible that future drug development focused on the discovery of AMPAR PAMs that are more selective for TARPs expressed in procognitive pathways may yield nootropic compounds with greater therapeutic windows.

\section{Acknowledgments}

We thank Dr. Makoto Kaneda (Nippon Medical School) and Drs. Christopher L. Shaffer and Michael Ehlers (Biogen, Inc.) for their input to and support of this project.

\section{Authorship Contributions}

Participated in research design: Ishii, Stolz, Swanson.

Conducted experiments: Ishii, Stolz.

Performed data analysis: Ishii, Stolz, Swanson.

Wrote or contributed to the writing of the manuscript: Ishii, Stolz, Swanson.

\section{References}

Arai A, Kessler M, Ambros-Ingerson J, Quan A, Yigiter E, Rogers G, and Lynch G(1996) Effects of a centrally active benzoylpyrrolidine drug on AMPA receptor kinetics. Neuroscience 75:573-585.

Arai A and Lynch G(1992) Factors regulating the magnitude of long-term potentiation induced by theta pattern stimulation. Brain Res 598:173-184.

Arai AC and Kessler M(2007) Pharmacology of ampakine modulators: from AMPA receptors to synapses and behavior. Curr Drug Targets 8:583-602.

Bednar MM, DeMartinis N, Banerjee A, Bowditch S, Gaudreault F, Zumpano L and Lin FR(2015) The safety and efficacy of PF-04958242 in age-related sensorineural hearing loss: a randomized clinical trial. JAMA Otolaryngol Head Neck Surg 141:607-613.

Black MD(2005) Therapeutic potential of positive AMPA modulators and their relationship to AMPA receptor subunits. A review of preclinical data. Psychopharmacology (Berl) 179:154-163.

Brorson JR, Manzolillo PA, Gibbons SJ, and Miller RJ(1995) AMPA receptor desensitization predicts the selective vulnerability of cerebellar Purkinje cells to excitotoxicity. J Neurosci 15:4515-4524.

Cais O, Herguedas B, Krol K, Cull-Candy SG, Farrant M, and Greger IH(2014) Mapping the interaction sites between AMPA receptors and TARPs reveals a role for the receptor N-terminal domain in channel gating. Cell Rep 9:728-740.

Chappell AS, Gonzales C, Williams J, Witte MM, Mohs RC, and Sperling R(2007) AMPA potentiator treatment of cognitive deficits in Alzheimer disease. Neurology 68:1008-1012.

Chen L, Chetkovich DM, Petralia RS, Sweeney NT, Kawasaki Y, Wenthold RJ, Bredt DS, and Nicoll RA(2000) Stargazin regulates synaptic targeting of AMPA receptors by two distinct mechanisms. Nature 408:936-943.

Chen S, Zhao Y, Wang Y, Shekhar M, Tajkhorshid E, and Gouaux E(2017) Activation and desensitization mechanism of AMPA receptor-TARP complex by cryo-EM. Cell 170:1234-1246.e14.

Cho CH, St-Gelais F, Zhang W, Tomita S, and Howe JR(2007) Two families of TARP isoforms that have distinct effects on the kinetic properties of AMPA receptors and synaptic currents. Neuron 55:890-904.

Coombs ID and Cull-Candy SG(2009) Transmembrane AMPA receptor regulatory proteins and AMPA receptor function in the cerebellum. Neuroscience 162: 656-665.

Dawe GB, Kadir MF, Venskutonyte R, Perozzo AM, Yan Y, Alexander RPD, Navarrete C, Santander EA, Arsenault M, Fuentes C, et al.(2019) Nanoscale mobility of the apo state and TARP stoichiometry dictate the gating behavior of alternatively spliced AMPA receptors. Neuron 102:976-992.e5.

Garthwaite G and Garthwaite J(1991) Mechanisms of AMPA neurotoxicity in rat brain slices. Eur J Neurosci 3:729-736.
Goff DC, Lamberti JS, Leon AC, Green MF, Miller AL, Patel J, Manschreck T, Freudenreich O, and Johnson SA(2008) A placebo-controlled add-on trial of the ampakine, CX516, for cognitive deficits in schizophrenia. Neuropsychopharmacology 33:465-472.

Goff DC, Leahy L, Berman I, Posever T, Herz L, Leon AC, Johnson SA, and Lynch G(2001) A placebo-controlled pilot study of the ampakine CX516 added to clozapine in schizophrenia. J Clin Psychopharmacol 21:484-487.

Granger R, Staubli U, Davis M, Perez Y, Nilsson L, Rogers GA, and Lynch G(1993) A drug that facilitates glutamatergic transmission reduces exploratory activity and improves performance in a learning-dependent task. Synapse 15:326-329.

Greger IH, Watson JF, and Cull-Candy SG(2017) Structural and functional architecture of AMPA-type glutamate receptors and their auxiliary proteins. Neuron $\mathbf{9 4}$ : $713-730$.

Hashimoto K, Fukaya M, Qiao X, Sakimura K, Watanabe M, and Kano M(1999) Impairment of AMPA receptor function in cerebellar granule cells of ataxic mutant mouse stargazer. J Neurosci 19:6027-6036.

Ingvar M, Ambros-Ingerson J, Davis M, Granger R, Kessler M, Rogers GA, Schehr RS, and Lynch G(1997) Enhancement by an ampakine of memory encoding in humans. Exp Neurol 146:553-559.

Ito I, Tanabe S, Kohda A, and Sugiyama H(1990) Allosteric potentiation of quisqualate receptors by a nootropic drug aniracetam. $J$ Physiol 424:533-543.

Jhee SS, Chappell AS, Zarotsky V, Moran SV, Rosenthal M, Kim E, Chalon S, Toublanc N, Brandt J, Coutant DE, et al.(2006) Multiple-dose plasma pharmacokinetic and safety study of LY450108 and LY451395 (AMPA receptor potentiators) and their concentration in cerebrospinal fluid in healthy human subjects. J Clin Pharmacol 46:424-432.

Jin R, Clark S, Weeks AM, Dudman JT, Gouaux E, and Partin KM(2005) Mechanism of positive allosteric modulators acting on AMPA receptors. $J$ Neurosci 25: 9027-9036.

Johansen TH, Chaudhary A, and Verdoorn TA(1995) Interactions among GYKI52466, cyclothiazide, and aniracetam at recombinant AMPA and kainate receptors. Mol Pharmacol 48:946-955.

Johnson SA, Luu NT, Herbst TA, Knapp R, Lutz D, Arai A, Rogers GA, and Lynch G(1999) Synergistic interactions between ampakines and antipsychotic drugs. J Pharmacol Exp Ther 289:392-397.

Kaae BH, Harpsøe K, Kastrup JS, Sanz AC, Pickering DS, Metzler B, Clausen RP, Gajhede M, Sauerberg P, Liljefors T, et al.(2007) Structural proof of a dimeric positive modulator bridging two identical AMPA receptor-binding sites. Chem Biol 14:1294-1303.

Kiss T, Hoffmann WE, and Hajós M(2011) Delta oscillation and short-term plasticity in the rat medial prefrontal cortex: modelling NMDA hypofunction of schizophrenia. Int $J$ Neuropsychopharmacol 14:29-42.

Lu W, Shi Y, Jackson AC, Bjorgan K, During MJ, Sprengel R, Seeburg PH, and Nicoll RA(2009) Subunit composition of synaptic AMPA receptors revealed by a singlecell genetic approach. Neuron 62:254-268.

Lynch G, Cox CD, and Gall CM(2014) Pharmacological enhancement of memory or cognition in normal subjects. Front Syst Neurosci 8:90.

Martin LJ, Blackstone CD, Levey AI, Huganir RL, and Price DL(1993) AMPA glutamate receptor subunits are differentially distributed in rat brain. Neuroscience 53:327-358.

Millan MJ, Agid Y, Brüne M, Bullmore ET, Carter CS, Clayton NS, Connor R, Davis S, Deakin B, DeRubeis RJ, et al.(2012) Cognitive dysfunction in psychiatric disorders: characteristics, causes and the quest for improved therapy. Nat Rev Drug Discov 11:141-168.

Milstein AD, Zhou W, Karimzadegan S, Bredt DS, and Nicoll RA(2007) TARP subtypes differentially and dose-dependently control synaptic AMPA receptor gating. Neuron 55:905-918.

Miu P, Jarvie KR, Radhakrishnan V, Gates MR, Ogden A, Ornstein PL, Zarrinmayeh H, Ho K, Peters D, Grabell J, et al.(2001) Novel AMPA receptor potentiators LY392098 and LY404187: effects on recombinant human AMPA receptors in vitro. Neuropharmacology 40:976-983.

Mosbacher J, Schoepfer R, Monyer H, Burnashev N, Seeburg PH, and Ruppersberg JP(1994) A molecular determinant for submillisecond desensitization in glutamate receptors. Science 266:1059-1062.

Partin KM(2015) AMPA receptor potentiators: from drug design to cognitive enhancement. Curr Opin Pharmacol 20:46-53.

Partin KM, Patneau DK, and Mayer ML(1994) Cyclothiazide differentially modulates desensitization of alpha-amino-3-hydroxy-5-methyl-4-isoxazolepropionic acid receptor splice variants. Mol Pharmacol 46:129-138.

Priel A, Kolleker A, Ayalon G, Gillor M, Osten P, and Stern-Bach Y(2005) Stargazin reduces desensitization and slows deactivation of the AMPA-type glutamate receptors. J Neurosci 25:2682-2686.

Ranganathan M, DeMartinis N, Huguenel B, Gaudreault F, Bednar MM, Shaffer CL, Gupta S, Cahill J, Sherif MA, Mancuso J, et al.(2017) Attenuation of ketamine-induced impairment in verbal learning and memory in healthy volunteers by the AMPA receptor potentiator PF-04958242. Mol Psychiatry 22: 1633-1640.

Riva I, Eibl C, Volkmer R, Carbone AL, and Plested AJ(2017) Control of AMPA receptor activity by the extracellular loops of auxiliary proteins. eLife $\mathbf{6}$

Roberts BM, Holden DE, Shaffer CL, Seymour PA, Menniti FS, Schmidt CJ, Williams $\mathrm{GV}$, and Castner SA(2010) Prevention of ketamine-induced working memory impairments by AMPA potentiators in a nonhuman primate model of cognitive dysfunction. Behav Brain Res 212:41-48.

Rouach N, Byrd K, Petralia RS, Elias GM, Adesnik H, Tomita S, Karimzadegan S, Kealey C, Bredt DS, and Nicoll RA(2005) TARP gamma-8 controls hippocampal AMPA receptor number, distribution and synaptic plasticity. Nat Neurosci 8 $1525-1533$

Shaffer CL(2018) Reverse and forward translational neuropharmacology in psychiatric drug discovery. Clin Pharmacol Ther 103:193-195. 
Shaffer CL, Hurst RS, Scialis RJ, Osgood SM, Bryce DK, Hoffmann WE, Lazzaro JT, Hanks AN, Lotarski S, Weber ML, et al.(2013) Positive allosteric modulation of AMPA receptors from efficacy to toxicity: the interspecies exposure-response continuum of the novel potentiator PF-4778574. J Pharmacol Exp Ther 347:212-224. Shaffer CL, Patel NC, Schwarz J, Scialis RJ, Wei Y, Hou XJ, Xie L, Karki K, Bryce DK, Osgood SM, et al.(2015) The discovery and characterization of the $\alpha$-amino-3 hydroxy-5-methyl-4-isoxazolepropionic acid (AMPA) receptor potentiator N-(3S,4S)-4 [4-(5-cyano-2-thienyl)phenoxy]tetrahydrofuran-3-ylpropane-2-sulfonamide (PF-04958242). $J$ Med Chem 58:4291-4308.

Shepherd TA, Aikins JA, Bleakman D, Cantrell BE, Rearick JP, Simon RL, Smith EC, Stephenson GA, Zimmerman DM, Mandelzys A, et al.(2002) Design and synthesis of a novel series of 1,2-disubstituted cyclopentanes as small, potent potentiators of 2-amino-3-(3-hydroxy-5-methyl-isoxazol-4-yl)propanoic acid (AMPA) receptors. J Med Chem 45:2101-2111.

Tomita S, Sekiguchi M, Wada K, Nicoll RA, and Bredt DS(2006) Stargazin controls the pharmacology of AMPA receptor potentiators. Proc Natl Acad Sci USA 103 10064-10067.

Trzepacz PT, Cummings J, Konechnik T, Forrester TD, Chang C, Dennehy EB, Willis BA, Shuler C, Tabas LB, and Lyketsos C(2013) Mibampator (LY451395) randomized clinical trial for agitation/aggression in Alzheimer's disease. Int Psychogeriatr 25:707-719.

Twomey EC, Yelshanskaya MV, Grassucci RA, Frank J, and Sobolevsky AI(2017) Channel opening and gating mechanism in AMPA-subtype glutamate receptors. Nature 549:60-65.

Yamazaki M, Fukaya M, Hashimoto K, Yamasaki M, Tsujita M, Itakura M, Abe M, Natsume R, Takahashi M, Kano M, et al.(2010) TARPs gamma-2 and gamma-7 are essential for AMPA receptor expression in the cerebellum. Eur $J$ Neurosci 31: $2204-2220$

Zasadny K, Callahan MJ, Kuszpit K, Chen L, Skaddan M, Brown-Proctor C, Harris R, Zhu A, Shaffer CL, and Scialis RJ(2009) FDG-PET imaging provides insights into efficacy and safety for an AMPA receptor potentiator (Abstract), World Mol Imaging Soc p 909

Address correspondence to: Geoffrey T. Swanson, Department of Pharmacology, Feinberg School of Medicine, Northwestern University, Chicago, IL 60611. E-mail: gtswanson@northwestern.edu 